\begin{tabular}{|c|l|}
\hline Title & Simulation of high concentration of iron in dense shelf water in the Okhotsk Sea \\
\hline Author(s) & $\begin{array}{l}\text { Uchimoto, Keisuke; Nakamura, Tomohiro; Nishioka, Jun; Mitsudera, Humio; Misumi, Kazuhiro; Tsumune, Dai suke; } \\
\text { Wakatsuchi, Masaaki }\end{array}$ \\
\hline Citation & $\begin{array}{l}\text { Progressin Oceanography, 126, 194.210 } \\
\text { https://doi.org/10.1016/.pocean.2014.04.018 }\end{array}$ \\
\hline Issue Date & 201408 \\
\hline Doc URL & http://hdl.handle.net/2115/56621 \\
\hline Type & article (author version) \\
\hline File Information & Uchimoto_etal_final.pdf \\
\hline
\end{tabular}

Instructions for use 


\section{Simulation of high concentration of iron in dense shelf water in the Okhotsk Sea}

3

4 Keisuke Uchimotoa, 1), Tomohiro Nakamurab), Jun Nishiokac), Humio

$5 \quad$ Mitsudera ${ }^{\mathrm{d})}$, Kazuhiro Misumi ${ }^{\mathrm{e})}$, Daisuke Tsumune ${ }^{\mathrm{f})}$, Masaaki Wakatsuchig)

6

7

a) Institute of Low Temperature Science, Hokkaido University, N19W8, Sapporo, 060-0819, Japan. E-mail: uchimoto@ rite.or.jp

b) Institute of Low Temperature Science, Hokkaido University, N19W8, Sapporo, 060-0819, Japan. E-mail: nakamura@lowtem.hokudai.ac.jp

c) Institute of Low Temperature Science, Hokkaido University, N19W8, Sapporo, 060-0819, Japan. E-mail: nishioka@ lowtem.hokudai.ac.jp

d) Institute of Low Temperature Science, Hokkaido University, N19W8, Sapporo, 060-0819, Japan. E-mail: humiom@ lowtem.hokudai.ac.jp

e) Environmental Science Research Laboratory, Central Research Institute of Electric Power Industry, 1646 Abiko, 270-1181, Japan. E-mail: misumi@ criepi.denken.or.jp

f) Environmental Science Research Laboratory, Central Research Institute of Electric Power Industry, 1646 Abiko, 270-1181, Japan. E-mail: tsumune@criepi.denken.or.jp

g) Institute of Low Temperature Science, Hokkaido University, N19W8, Sapporo, 060-0819, Japan. E-mail: masaakiw@lowtem.hokudai.ac.jp

1) Present address: Research Institute of Innovative Technology for the Earth, 9-2, Kizugawadai, Kizugawa, 619-0292, Japan.

Corresponding author:

Keisuke Uchimoto

Research Institute of Innovative Technology for the Earth

9-2, Kizugawadai, Kizugawa, 619-0292, Japan.

TEL: +81-774-75-2312

E-mail: uchimoto@rite.or.jp 
34 Keywords: Sea of Okhotsk; iron; simulation; DSW; sedimentary iron 35

36 


\section{$37 \quad$ Abstract}

38 An ocean general circulation model coupled with a simple biogeochemical model was developed to simulate iron circulation in and around the Sea of Okhotsk. The model has two external sources of iron: dust iron at the sea surface and sedimentary iron at the seabed shallower than $300 \mathrm{~m}$. The model represented characteristic features reasonably well, such as high iron concentration in the dense shelf water (DSW) and its mixing, which extends southward in the intermediate layer from the northwestern shelf along

44 Sakhalin Island and finally flows into the Pacific. Sensitivity experiments for the solubility of dust iron in seawater suggest that a solubility of $1 \%$ is appropriate in our simulation. Higher solubilities (5\% and 10\%) result in too low phosphate in the northwestern North Pacific in summer as well as too high iron concentrations at the sea surface, compared with observations. Besides, these experiments show that dust iron hardly contributes to the high iron concentration in the intermediate layer. To investigate locations from which the iron in the intermediate layer originates, the fate of sedimentary iron input from four regions in the Okhotsk Sea was examined. Results suggest that the western and central parts of the northern shelf are important. 
The Sea of Okhotsk (Fig. 1) has attracted the attention of oceanographers as an important source region of iron, particularly since Nishioka et al. (2007) hypothesized that the northern part of the Sea of Okhotsk is a main source region of iron to the western subarctic Pacific, which is one of the characteristic areas having high-nutrient and low-chlorophyll (HNLC) owing to iron deficiency (Tsuda et al., 2003; Tsuda et al., 2007). The hypothesis of Nishioka et al. (2007) has been confirmed by Nishioka et al. (2014), whose observational data clearly show that a large amount of iron is transported with dense shelf water (DSW) through the intermediate layer. In addition, they showed that iron is vertically homogeneous at the Bussol' Strait, the main source of outflow to the Pacific. This is caused by strong tidal mixing there (Nakamura and Awaji, 2004). Recently, Misumi et al. (2011) succeeded in simulating the major observed features of the iron distribution in the North Pacific, such as the high concentration in the intermediate layer in the northwestern Pacific and off California. The maximum concentration layer at the intermediate depths along $165^{\circ} \mathrm{E}$ is also reproduced. Their success is owed to introduction of the sedimentary iron source, which was not considered in previous simulations (e.g., Archer and Johnson, 2000; Parekh et al., 2005). However, the depth of the maximum concentration layer is shallower than observations. Because this high concentration of iron in the intermediate layer is associated with the North Pacific Intermediate Water (NPIW; Nishioka et al., 2007), the shallower depths of the iron maximum layer in their simulation may be attributed to the insufficient expression of ventilation processes in the Sea of Okhotsk, which is the origin of NPIW.

In the present study, we have developed a biogeochemical-physical coupled model, and simulated the iron distribution in the Sea of Okhotsk. The physical part of 
the model (ocean general circulation model) includes the effects of two ventilation processes in the Sea of Okhotsk. One process is brine rejection during sea ice formation. DSW is produced based on it in the northwestern part of the Sea of Okhotsk (e.g. Kitani, 1973; Shcherbina et al., 2003), and flows in the intermediate layer, which is a layer with the potential density around $26.8 \sigma_{\theta}$, to the Pacific (e.g. Fukamachi et al., 2004). The other is tidal mixing along the Kuril Islands (e.g. Nakamura et al., 2006). Using the physical part of this model, Uchimoto et al. (2011a; b) successfully reproduced DSW and the distribution of chlorofluorocarbons, respectively. The biogeochemical part is based on Parekh et al. (2005)'s model. Although Parekh's model is one of the simplest biogeochemical models including iron, it succeeded to reproduce the iron distribution pattern.

This study focuses on the high concentration of iron in the intermediate layer along Sakhalin, the western boundary of the Sea of Okhotsk. We will demonstrate that the model including the ventilation processes is able to reproduce the high concentration of iron, and suggest that the iron originates mainly from sediment on the seabed in the Sea of Okhotsk, as is consistent with the suggestion by Nishioka et al. (2007). Furthermore, it remains to be answered where and how much sedimentary iron is supplied. To give a clue to the answer to this question, we conducted sensitivity experiments.

Recent biogeochemical models improve ecosystem dynamics; for example, Moore and Braucher (2008), Misumi et al. (2011) and Galbraith et al. (2010) consider a few classes of phytoplankton, and Galbraith et al. (2010) consider complex light limitation combined with iron limitation. In Parekh's model, on the other hand, they are simply parameterized. In this study, the high concentration of iron in the intermediate 
layer is focused on, where iron that is decoupled from nutrient cycles (e.g. external sources of iron) is thought to be important (Nishioka et al., 2007; 2014). We consider that the simple Parekh's model, where iron interacts with phosphorus but is decoupled through scavenging, complexation with ligands and external sources, is useful to clarify the role of iron sources in the continental shelf, although the model is too simple to represent the detailed iron distribution owing to, for example, uptake by various phytoplankton.

In the next section, the model is outlined. In section 3, some parameters in the biogeochemical model are determined through sensitivity experiments. Section 4 describes the iron distribution in the simulation, and section 5 describes the experiments. Some parameters of the scavenging formulation and effects of sea ice are discussed in section 6 . Section 7 concludes the paper.

\section{Model}

The model used is a biogeochemical-physical coupled model. The physical part of the model is the same as that used by Uchimoto et al. (2011a; b). The biogeochemical part is based on Parekh et al. (2005)'s model, but some parameter values are changed, and sedimentary iron flux is newly brought in. The attenuation of irradiance by sea ice is also considered because sea ice covers large areas of the Sea of Okhotsk in winter. Parameter values different from or absent in the simulation by Parekh et al. (2005) are given in Table 1. We shall give a brief description below. For details refer to Parekh et al. (2005) and Uchimoto et al. (2011a; b).

\subsection{Physical part of the model}

The physical part of the model is based on Center for Climate System Research 
Ocean Component Model (COCO) version 3.4, which includes a sea ice model (Hasumi,

127 2006). The model domain extends from $136^{\circ} \mathrm{E}$ to $179.5^{\circ} \mathrm{W}$ and $39^{\circ} \mathrm{N}$ to $63.5^{\circ} \mathrm{N}$ (Fig. 1), with 51 vertical levels. The horizontal grid spacing is $0.5^{\circ}$, and the vertical spacing increases from $1 \mathrm{~m}$ near the surface to $1000 \mathrm{~m}$ at the deepest level. The isopycnal and thickness diffusion coefficients (Cox, 1987; Gent et al., 1995) are $1.0 \times 10^{6}$ and $3.0 \times 10^{6}$ $\mathrm{cm}^{2} / \mathrm{s}$, respectively, and the background vertical viscosity and diffusion coefficients are

1321.0 and $0.1 \mathrm{~cm}^{2} / \mathrm{s}$, respectively. As tides are not included in the model, vertical diffusivity coefficients increased along the Kuril Islands to represent the vertical mixing caused by tidal currents over the bottom relief. The increment of the coefficient is set $500 \mathrm{~cm}^{2} / \mathrm{s} \mathrm{at}$ the bottom and decreases upward. The sea ice model adopts a two category thickness representation (Semtner, 1976) and an elastic-viscous-plastic rheology formulation (Hunke and Dukowicz, 1997). The physical part is forced by daily climatological atmospheric data of the Ocean Model Intercomparison Project (OMIP; Röske, 2001). Potential temperature and salinity are restored to the values in WOA01 (Conkright et

140 al., 2002) at five grid points and the surface elevation is restored to the output of a basin 141 wide model at three grid points from the open boundaries. Also, potential temperature 142 and salinity at grid points deeper than about $2000 \mathrm{~m}$ and sea surface salinity are restored to the WOA01 with 10 days and 60 days of restoring time, respectively. This physical model is coupled with a biogeochemical model at July after a 116 year spinup. 2.2 Biogeochemical part of the model

147 Figure 2 represents the phosphorus cycle schematically. The water column is vertically 148 divided into two parts. The biological process occurs only in the upper layer, which we 149 refer to as the euphotic layer. The depth of the euphotic layer is fixed at $135 \mathrm{~m}$ 
independent of the light condition, and so the definition of the euphotic layer may be different from a common one. Prognostic variables for phosphorus are phosphate $\left(\mathrm{PO}_{4}\right)$ and dissolved organic phosphorus (DOP), while the only prognostic variable for iron is total dissolved iron (and thus total dissolved iron will be referred to as iron (or Fe) hereafter). The advection and diffusion of $\mathrm{PO}_{4}, \mathrm{DOP}$, and iron are calculated from the physical part of the model, with source/sink terms calculated by the biogeochemical model. $\mathrm{Fe}$, and light (I: the solar shortwave irradiance) in Michaelis-Menten kinetics; $\Gamma=\alpha \frac{\mathrm{PO}_{4}}{\mathrm{PO}_{4}+\mathrm{K}_{\mathrm{PO}}} \frac{\mathrm{Fe}}{\mathrm{Fe}+\mathrm{K}_{\mathrm{Fe}}} \frac{\mathrm{I}}{\mathrm{I}+\mathrm{K}_{\mathrm{I}}}(1)$, where $\alpha$ is the maximum export rate, $\mathrm{KX}$ is the half saturation constant of $\mathrm{X}\left(\mathrm{X}\right.$ is $\mathrm{PO}_{4}$, $\mathrm{Fe}$, or I), and $\mathrm{K}_{\mathrm{PO} 4}, \mathrm{~K}_{\mathrm{Fe}}$, and $\mathrm{K}_{\mathrm{I}}$ are $0.5 \mu \mathrm{M}, 0.12 \mathrm{nM}$, and $30 \mathrm{Wm}^{-2}$, respectively. We shall discuss values of $\alpha$ and $\mathrm{K}_{\mathrm{Fe}}$ in section 3.2. Part of phosphate uptaken in the euphotic layer $(v \Gamma)$ enters the DOP pool at the same grid point, and the remainder, $(1-v) \Gamma$, is exported as particulates to the layer deeper than the euphotic layer. DOP is continuously remineralized with an e-folding scale of 6 months, independent of light condition, i.e., in both the euphotic layer and the deeper layer. The vertical flux of the particulates due to sinking, F(z), is expressed in the Martin et al. (1987)'s power law, and the remineralization is expressed as the convergence of the flux, $\frac{\partial \mathrm{F}}{\partial \mathrm{z}}$. Particulates that reach the bottom (the deepest grid points) are remineralized there. Daily mean irradiance data are used, and irradiance decays exponentially from the sea surface downward with a $30^{-} \mathrm{m}$ length scale in (1). This length scale makes irradiance at $135 \mathrm{~m}$ (i.e. the bottom of the euphotic layer) about $1.1 \%$ of that at the sea 
surface. The decay owing to sea ice is represented as

$I_{b}=\left(1-r_{I}\right) I_{0} e^{-\kappa h_{I}}$,

where $I_{b}$ and $I_{0}$ are irradiance at the bottom of ice (the surface of water) and the surface of ice, respectively, $r_{I}$ is albedo, and $h_{I}$ is the thickness of ice. The decay scale, $\kappa^{-1}$, is $1.5 \mathrm{~cm}$ (Perovich, 1998). When ice is thinner than $20 \mathrm{~cm}$, it is regarded as young ice and its albedo is set as 0.36. For other ice, albedo is set as 0.7 (Nihashi et al., 2011). In the water column under sea ice, $I_{b}$ decays with a 30-m length scale.

The iron cycle has both biological and external source/sink terms. The biological uptake, export and remineralization in the iron equation are proportional to those in the phosphate equation. The proportionality coefficient, $R_{\mathrm{Fe}}$, is fixed as $R_{\mathrm{Fe}}=$ 0.47 mmol Fe:mol P (Parekh et al., 2005). This ratio is the same as that required by a dominant Fe limited phytoplankton in the subarctic Pacific (Marchetti et al., 2006). The external sources of the aeolian dust and the bottom sediment, and sink by scavenging (scav) are considered, which decouple the iron cycle from the phosphate cycle. The aeolian dust input data is based on the monthly dust deposition data from a simulation by Mahowald et al. (2005) (Fig. 3). We assume that iron is 3.5 weight\% of dust and that it dissolves instantaneously at the sea surface with the solubility in seawater $1 \%$. We shall discuss the sensitivity to solubility of dust iron in section 3.1. We assume that sea ice is transparent to the dust iron, that is the dust iron enters the sea even if sea ice covers the sea. The sedimentary flux of iron is applied at the seabed (the deepest grid point) shallower than $300 \mathrm{~m}$. Although some biogeochemical models (e.g. Moore and Braucher, 2008) estimate the sedimentary flux of iron based on Elrod et al. (2004), not all the sedimentary fluxes match their relationship as reported by Homoky et al. (2013). In this study, we adopt a constant flux that is used in simulations, for example, by 
Parekh et al. (2008), and we set the constant value $1 \mu \mathrm{mol} \mathrm{Fe} \mathrm{m}^{-2} \mathrm{~d}^{-1}$ according to

198 Parekh et al. (2008). Iron input from the Amur River is implicitly included in the model as part of the sedimentary iron since both suspended matter including iron and dissolved iron from the Amur River are thought to flocculate and settle near the river mouth and subsequently be carried to the northwestern shelf region (Boyle and Edmond, 1977; Shigemitsu et al., 2013), which is also supported by Nishioka et al. (2014). Scavenging acts only on the free form of iron as scav $=-\tau k_{0} C_{p}^{\phi} \mathrm{Fe}^{\prime}$. Total dissolved iron in this model is assumed to be the sum of complexed ( $\mathrm{FeL}$ ) and free forms $(\mathrm{Fe})$, and $C_{p}$ is the particle concentration calculated using the relationship, $\mathrm{F}(\mathrm{z})=C_{p} W_{\text {sink }}$, where $W_{\text {sink }}$ is a particle sinking rate and is $2900 \mathrm{~m} / \mathrm{y}$ (Parekh et al., 2005). The scavenging rate, $k_{0}$, and a constant $\phi$ are 0.58 and 0.079 , respectively, which are based on the study by Honeyman et al. (1988), and a scavenging scaling factor, $\tau$, is 0.2 according to Parekh et al. (2005). To calculate Fe', we use an equilibrium relationship $K_{\mathrm{FeL}}=[\mathrm{FeL}] /\left[\mathrm{Fe}^{\prime}\right]\left[\mathrm{L}^{\prime}\right]$, where $\mathrm{L}$ represents ligands. We set $\mathrm{K}_{\mathrm{FeL}}$, the conditional stability coefficient, as $1.0 \times 10^{11}$, and assume that the total ligand concentration, i.e. the sum of FeL and L', is $1.2 \mathrm{nM}$ by reference to the study by Misumi et al. (2011). Phosphate and iron are restored to the boundary condition data at five grid points from lateral boundaries. The initial and boundary conditions of $\mathrm{PO}_{4}$ are monthly average data of the World Ocean Atlas 2009 (WOA09; Garcia et al., 2010). DOP is set to be 0 at the initial condition and along the lateral boundaries. There are no sink or source of phosphorus in this biogeochemical model, and so phosphorus is preserved if the model domain is closed. However because of the open lateral boundaries, phosphorus is not preserved in this model. 
produced in reference to observational data by Takata et al. (2008) for the Sea of Japan, and Nishioka et al. $(2007,2013)$ for the Pacific and the results of a simulation by Misumi et al. (2011) for the Bering Sea. In the Sea of Japan and the southern boundary in the Pacific, the boundary concentration data are horizontally constant as shown in Fig. 4. The Misumi et al. (2011)'s data are somewhat revised by reference to the data observed in the Bering Sea by Takata et al. (2005). The boundary conditions of iron are temporally constant. We use the southern boundary iron concentration as the initial condition for the whole model region.

In the following sections, the figures are the monthly mean of the 18 th year after the coupling the biogeochemical model with the physical model as at least, within the Sea of Okhotsk, the spatial pattern reaches almost an equilibrium.

\section{Sensitivity to parameters in the biogeochemical model}

\subsection{Solubility of dust iron at the sea surface}

Dust iron solubility at the sea surface is one of the unknown parameters. There are too many factors and processes that control the solubility to determine a proper value for simulations, and not all of those factors and processes have been clarified (e.g. Baker and Croot, 2010). In fact, the dust iron solubility estimates from iron dissolution experiments, using sampled dust, range widely. In the northwestern Pacific, for example, Buck et al. (2006) estimates it as $6 \pm 5 \%$, while Ooki et al. (2009) suggests that it is around $0.4 \%$. Although Parekh et al. (2005) set it as $1 \%$, we should examine the sensitivity to it. We conducted experiments with the dust iron solubility of $0 \%, 1 \%, 5 \%$, and $10 \%$. Probably the solubility is not constant over the whole area of the model, as is seen, for example, in the model experiment by Fan et al. (2006). It is, however, assumed 
to be constant both temporally and spatially in the present study.

The higher solubility leads to the higher iron concentration because of the increase of total iron input (Figs. 6 and 7). The increase of iron in the intermediate layer is, however, relatively small (Fig. 7), whereas the increase at the sea surface is significant (Fig. 6). These imply that the dust iron is less important for the intermediate layer than the sedimentary iron, at least based on the present model configurations. from the simulated iron concentration in Figs. 6 and 7 because of the lack of observations, although the iron concentration at the sea surface in the case with the solubility of $10 \%$ is obviously too high compared with the limited observations (not higher than $1.0 \mathrm{nM}$ in the northwestern Pacific; e.g. Nishioka et al., 2007). We, therefore, use the concentration of phosphate to determine the value of iron solubility. the WOA09 (Fig. 8c), when the spring bloom has finished, is a sharp contrast between the Sea of Okhotsk and the Pacific. The concentration is low in the former and high in the latter because phosphate is not completely consumed owing to the deficiency of iron in the Pacific. The contrast also appears in the results of experiments (Fig. 9a-d). However, the concentration in the Pacific becomes significantly lower than the observed values as the solubility of iron increases to $5 \%$ or $10 \%$. Thus, we consider that $1 \%$, used by Parekh et al. (2005), is also reasonable in the present model.

These experiments also show that the present model is able to represent the HNLC feature caused by iron deficiency in the subarctic Pacific. Phosphate is not depleted in the subarctic Pacific even after the spring bloom, which is a feature of HNLC areas. It decreases as the solubility of iron increases, which indicates that this 
area is deficient in iron when the solubility is low. In contrast, the concentration of phosphate in the Sea of Okhotsk is low in July and changes little even when the solubility of iron increases. This shows that the Sea of Okhotsk in this model is not an HNLC region nor iron-limited region, which is consistent with an observational study by Nakatsuka et al. (2004).

\subsection{Parameters in biological uptake term}

Although the half saturation constant of $\mathrm{Fe}, \mathrm{K}_{\mathrm{Fe}}$, in eq. (1) is set to be $0.12 \mathrm{nM}$ in the study by Parekh et al. (2005), it may be small for the northwestern Pacific. We set it as $0.5 \mathrm{nM}$ by reference to the study of Noiri et al. (2005). Although the maximum export rate, $\alpha$, is set to be 0.5 in the study by Parekh et al. (2005), we tuned the value of $\alpha$, to represent more clearly the difference in the features of an HNLC region; the Pacific in this model region is an HNLC region while the Sea of Okhotsk is not an HNLC region.

Figure 10 shows phosphate distribution at the sea surface in July. In the case with the original Parekh's $\mathrm{K}_{\mathrm{Fe}}$ and $\alpha$ values $\left(\mathrm{K}_{\mathrm{Fe}}=0.12 \mathrm{nM}\right.$, and $\left.\alpha=0.5\right)$, phosphate concentration (Fig. 9b) is somewhat smaller in the Pacific and somewhat larger in the Sea of Okhotsk than that in the WOA09 (Fig. 8c). The concentration increases over the entire region when $\mathrm{K}_{\mathrm{Fe}}$ increases to $0.5 \mathrm{nM}$ (Fig. 10a). As $\alpha$ increases (Figs. 10b and 10c), the concentration decreases, particularly in the Sea of Okhotsk. Compared with the WOA09, the distribution in Fig. 10c is the most reasonable one: the phosphate is almost depleted in the Sea of Okhotsk and not depleted in the Pacific. Thus, we set $\mathrm{K}_{\mathrm{Fe}}$ and $\alpha$ as $0.5 \mathrm{nM}$ and 1.0 , respectively.

There is also a need to discuss the dependence of the iron distribution on the 
formulation of scavenging and its parameters, which will be discussed in section 6 .

294

\section{Standard case}

Using the parameter values determined in section 3 , we conducted a simulation, which we refer to as the standard case. Iron distributions on the $26.8 \sigma_{\theta}$ isopycnal surface in January, April, July, and October are shown in Fig. 11a-d. The high concentration area extends along the northern and the western coasts of the Sea of Okhotsk in all seasons. This suggests that iron is transported from the northern part by the cyclonic circulation, which is the characteristic circulation in a large part of the Sea of Okhotsk (e.g. Ohshima et al., 2004).

A high concentration of iron is seen in the intermediate layer, between $26.8 \sigma_{\theta}$ and $27.0 \sigma_{\theta}$, in the vertical section (Fig. 11e-h) along the red solid line shown in Fig. 12a, which we call the DSW line hereafter. This line is approximately along the path of DSW. Since the core density of DSW in this model is $26.9 \sigma_{\theta}$ (Uchimoto et al., 2011b), the high concentrations extending from the bottom of the shelf in Fig. 11e-h corresponds to DSW.

The observational data by Nishioka et al. (2013; 2014) represent very high concentration of iron in the northwestern part of the Sea of Okhotsk, and the maximum of the dissolved iron concentration in the intermediate layer within the Sea of Okhotsk. These features are also seen in the simulated iron concentration in Fig. 11e-h. The simulated data are in good agreement with the observed data shown in Figure 13. The above iron distribution is qualitatively similar to that of chlorofluorocarbons simulated by Uchimoto et al. (2011b). This implies that iron in the intermediate layer is distributed by ocean currents from the northern shelf and the Kuril Straits.

Figure 14 shows the simulated phosphate distribution at the sea surface. 
317 Although the concentration is somewhat lower than the WOA09 data in Fig. 8, seasonal

318 variations in the Sea of Okhotsk are represented. During summer to early winter the

319 phosphate concentration is low and during late winter and spring, it is high. Figure 15

320 shows the vertical section of phosphate concentration along the DSW line. The

321 concentration of phosphate in the intermediate layer is similar as that of WOA09 (Fig.

322 16), although the simulated concentration near the surface is somewhat lower and that

323 in the deeper layer is somewhat higher than that of WOA09. Figure 17 shows the

324 simulated DOP distribution along the DSW line. In contrast with the phosphate

325 concentration, the DOP concentration in the surface layer is relatively low in January

326 and April (Fig. 17a, b) and high in July and October (Fig. 17 c, d). This is thought to be

327 due to the time scale of the remineralization of DOP. The concentration of DOP in the

328 intermediate layer is low. It is about $0.3 \mu \mathrm{M}$ in the northwestern shelf area and no more

329 than $0.05 \mu \mathrm{M}$ in the other areas in Fig. 17. As $R_{F e}=0.47 \mathrm{mmol} \mathrm{Fe}: \mathrm{mol} \mathrm{P}$, the

330 contribution of the DOP remineralization term to the iron concentration is negligible in

331 the intermediate layer.

332 If sedimentary iron is not given, the high concentration of iron along the path

333 of DSW is not reproduced. Iron concentration is not higher in the western part than the other areas on the $26.8 \sigma_{\theta}$ surface (Fig. 12a), and the iron concentration maximum is not seen in the intermediate layer along the DSW line (Fig. 12b). These results support the hypothesis that the high concentration of iron in DSW primarily originates from the sediments, instead of from aeolian dust.

As shown above, the sedimentary iron is an important source of iron 
concentration in the intermediate layer of the Sea of Okhotsk. Nakatsuka et al. (2002) reported that a large amount of particles are incorporated into DSW on the northwestern shelf. Iron would be also entrained into DSW there, and thus the northwestern shelf is a likely source region of the sedimentary iron, as is suggested by Nishioka et al. (2007). However it is still an open question whether the northwestern shelf is the only source area for the iron in DSW. We attempt to estimate the relative contribution of shelf regions through sensitivity experiments, although future observations are needed to confirm it. almost evenly, as shown in Fig. 18, and changed the sedimentary iron flux in each part. Here, the continental shelf is defined as regions with water depth less than $300 \mathrm{~m}$, and is divided into the northwestern shelf (denoted as NW), the central and eastern parts of the northern shelf ( $\mathrm{NC}$ and $\mathrm{NE}$, respectively), and the others (OT). OT thus consists of two regions along the eastern and the western boundaries in the Sea of Okhotsk. Several series of numerical experiments (Table 2) were conducted to clarify the contribution of sedimentary iron in each part to iron concentration in the intermediate layer. In a case denoted as AAy, sedimentary iron flux is given in the AA part (e.g. NW) at a rate of y $\mathrm{\mu mol} \mathrm{Fe} \mathrm{m}^{-2} \mathrm{~d}^{-1}$. For comparison, no sedimentary iron flux is given in NoSed case, and $1 \mu \mathrm{mol} \mathrm{Fe} \mathrm{m}{ }^{-2} \mathrm{~d}^{-1}$ is given in all the shelf in the Sea of Okhotsk in ALL1 case. Note that the experiments in the present section were conducted without the sedimentary iron in the Pacific and the dust iron source to clarify the effect of the sedimentary iron within the Sea of Okhotsk. 
sedimentary iron from respective sources spreads. The sedimentary iron in each case spreads cyclonically from the source region, with its concentration decreased. In NW1 and NC1 cases (Figs. 19a and 19b), the concentration is relatively high off the east coast of Sakhalin (around the path of DSW), but in NE1 case (Fig. 19c) it is low compared with NW1 and NC1 cases.

In Fig. 20, iron concentrations in DSW on $50^{\circ} \mathrm{N}$ are plotted against the sedimentary iron flux (SedFe) given in each part. Here, we define DSW as a watermass with potential temperature less than $1.2^{\circ} \mathrm{C}$ and with potential density between 26.8 and $27.0 \sigma \theta$, excluding OT area. The iron concentration in DSW increases almost proportionally to SedFe, when SedFe is larger than $1 \mu \mathrm{mol} \mathrm{m} \mathrm{m}^{-2} \mathrm{~d}^{-1}$ for each part (e.g. NW2-NW10). However, the concentration in the NE cases increases only slightly. This result, as well as Fig. 19c, indicates that sedimentary iron supplied in the eastern part of the northern shelf hardly contributes to the concentration of iron in DSW. Iron in DSW originates mostly from the central and the western part of the northern shelf region, and the path of DSW (i.e. the western part of OT). when the source flux increases by $1 \mu \mathrm{mol} \mathrm{m}{ }^{-2} \mathrm{~d}^{-1}$ in the NW case, that is, the differences of iron concentration between NW2 and NW1, NW3 and NW2, NW4 and NW3, and, NW5 and NW4. Both the magnitude and spatial extent of the increment are similar when the flux is larger than $3 \mu \mathrm{mol} \mathrm{m}^{-2} \mathrm{~d}^{-1}$ (Figs. 21b-d). This is also true in the NC, NE, and OT cases (not shown). The concentration not only in DSW at $50^{\circ} \mathrm{N}$ (Fig. 20) but the other areas increases nearly proportionally to the flux of iron given at the bottom. 
show an increase of iron concentration resulting from an increase of source iron by 1 $\mu \mathrm{mol} \mathrm{m} \mathrm{m}^{-2} \mathrm{~d}^{-1}$ in NW case, but unlike Fig. 21, with an ambient iron concentration coming from sedimentary iron in other areas (NC, NE and OT). These figures are reasonably similar to Figs. 21b-d; particularly Fig. 22a is similar to Fig. 21d, and Fig. 22b is similar to Fig. 21c. Because the areas of NW, NC, NE, and OT regions are roughly the same, the total iron input in NW2O1, ALL1, and NW0O1 is roughly the same as that in NW5, NW4 and NW3, respectively. This suggests that when the total iron input is the same, the increment of iron input in a certain area leads to roughly the same increment in iron concentration. associated with the scavenging. As shown in Fig. A1 (c) in the paper by Misumi et al. (2011), scavenging intensity is proportional to total dissolved iron when the total dissolved iron concentration is higher than the total ligand concentration. Physical processes also contribute to the change of iron concentration. In the same current fields, however, their contribution is only the convergence of iron flux, which is also proportional to iron concentration. Thus, iron concentration is thought to increase almost proportionally to iron input.

\section{Discussion}

In this study, parameters in scavenging formulation are the same as the simulation by Parekh et al. (2005) except for the total ligand concentration. Here, we confirm that the high concentration of iron in the intermediate layer along the DSW line is independent of scavenging parameters, a scavenging scaling factor, $\tau$, and a particle sinking rate, $W_{\text {sink }}$. We conducted 4 numerical experiments with half and double values 
413 of $\tau$ and $W_{\text {sink }}$, respectively, of the standard case, where $\tau$ is 0.2 , and $W_{\text {sink }}$ is 2900

$414 \mathrm{~m} / \mathrm{y}$. In each experiment, other conditions are the same as in the standard case. The iron concentration increases(decreases) overall when $\tau$ becomes small(large) and $W_{\text {sink }}$ becomes large(small) (Fig. 23, 24). However, in all cases, the concentration in the intermediate layer is high. As shown in Fig. 13, the iron concentration in the intermediate layer is consistent with observations in the standard case, and therefore, the values $\tau=0.2$ and $W_{\text {sink }}=2900 \mathrm{~m} / \mathrm{y}$ chosen in this study are considered to be reasonable.

The simple formulation of scavenging in this model may, however, lead to disagreement of the simulated iron concentration with observational data near the surface and the deep layer as shown in Fig. 13. Although in this formulation, scavenged iron is completely lost, that is, scavenging is a sink of iron, the scavenged iron is actually remineralized within the water column, which is formulated in some models (e.g. Moore and Braucher, 2008). In addition, only the scavenging by particles is considered and that by lithogenic materials (Moore and Braucher, 2008; Galbraith et al., 2010) is not considered in our model. These may cause a lower concentration of iron in deep layer than the observation. Higher concentration near the surface in our simulation than the observation may suggest that scavenging there in this model is too weak. Moore and Braucher (2008) increased the scavenging rate near the surface, and Galbraith et al. (2010) changed the ligand stability constant vertically, which results in strong scavenging near the surface. Ye et al. (2011) suggest that colloidal aggregation is an important factor for eliminating dissolved iron. includes the attenuation of irradiance and does not include effects of the prevention of 
dust iron entering the sea. In practice, the dust iron is accumulated in the sea ice and transported southward. The supply of the iron from sea ice in its melting season greatly affects the iron concentration in the surface layer in the Sea of Okhotsk (e.g. Kanna et al., 2014). Our model may overestimate the supply of iron at the sea surface covered with sea ice, and underestimate the supply of iron in the surface layer where and when the sea ice melts. However, these might not greatly influence the concentration of iron in the intermediate layer in the present model since the contribution of iron supplied at the sea surface to the intermediate layer is small in this model as shown in Fig. 7.

\section{Concluding remarks}

We have developed a biogeochemical-physical coupled ocean model to simulate the iron transport and distribution in the Sea of Okhotsk, particularly the high concentration of iron in the intermediate layer, which recent observations have revealed (Nishioka et al., 2007; 2014). The physical part of the model is that of Uchimoto et al. (2011a, b), which well represents the ventilation and the circulation of the intermediate layer in the Sea of Okhotsk. The geochemical part is based on Parekh et al. (2005)'s model, where the iron cycle interacts with the phosphorus cycle but is decoupled through external sources and sink terms.

Although the present biogeochemical model is not complex, we have succeeded in reproducing the important features regarding the iron distribution in the Sea of Okhotsk and the northwestern Pacific; such as the high concentration of iron in DSW in the Sea of Okhotsk, the HNLC feature in the northwestern Pacific caused by iron deficiency, and not HNLC in the Sea of Okhotsk. Through the numerical experiments, it was suggested that the high concentration of iron in DSW is attributed mainly to the 
bottom sedimentary iron, not to aeolian dust. However, it should be noted that the present model is not sufficiently complex to be able to represent the detailed iron distribution owing to, for example, ligand distribution, various biological iron uptake processes, and transport of iron by sea ice. There is also uncertainty in the amount of dust iron input and the sedimentary iron input. However, the increase of dust iron input effects a relatively small change in the iron concentration of the intermediate layer in the present model configuration as shown in section 3.1. On the other hand, the sedimentary flux of iron increases the iron concentration of the intermediate layer.

Several series of numerical experiments showed that the iron concentration in DSW increases as the sedimentary iron fluxes in the western and eastern part of the northern shelf (NW, NC) and along the DSW (the western part of OT) increase, but that it hardly increases even if the flux in the eastern part of the northern shelf (NE) increases. This implies that the eastern part of the northern shelf is so far from the path of DSW that much of the iron supplied there is scavenged before it reaches the path of DSW in this model configuration.

Although the present model reasonably reproduced features of the iron distribution in the Sea of Okhotsk, many important parameters, such as iron dust solubility, remain uncertain and thus they were determined through sensitivity experiments. Recently, iron in the Sea of Okhotsk has attracted attention, and many observations have been and will be conducted, which will help the model improvement.

\section{acknowledgements}

We are grateful to N. Mahowald for providing us with the dust dataset. We also thank Y. Hoshiba for his helpful comments on constructing the model. An anonymous reviewer's 
485

486

487

488

489

490

491

492

493

494

495

496

497

498

499

500

501

502

503

504

505

506

507

508

thoughtful and constructive comments greatly improved the manuscript. Numerical calculations were performed at the Pan-Okhotsk Information System of Institute of Low

Temperature Science, Hokkaido University and the high performance computing system at information initiative center, Hokkaido University. This study was supported by the New Energy and Industrial Technology Development Organization (NEDO), JHPCN and the grant-in-aid for Scientific Research (KAKENHI) No. 222210001 and No. 22106010. The figures were produced by GFD-DENNOU Library (http://www.gfd-dennou.org/index.html.en).

\section{References}

Archer, D. E., Johnson, K., 2000. A model of the iron cycle in the ocean. Global Biogeochem. Cycles, 14(1), 269-279, doi:10.1029/1999GB900053.

Baker, A. R., Croot, P. L., 2010. Atmospheric and marine controls on aerosol iron solubility in seawater. Mar. Chem., 120, 4-13.

Boyle, E. A., Edmond, J. M., 1977. The mechanism of iron removal in estuaries. Geochimica et Cosmochimica Acta, 41, 1313-1324.

Buck, C. S., Landing, W. M., Resing, J. A., Lebon, G. T., 2006. Aerosol iron and aluminium solubility in the northwest Pacific Ocean: Results from the 2002 IOC cruise. Geochem. Geophys. Geosyst., 7, Q04M07, doi:10.1029/2005GC000977.

Conkright, M. E., Locarnini, R. A., Garcia, H. E., O’Brien, T. D., Boyer, T. P., Stephens, 
512 Cox, M. D., 1987. Isopycnal diffusion in a z-coordinate ocean model. Ocean Modelling 74, $1-5$.

Elrod, V. A., Berelson, W. M., Coale, K. H., Johnson, K. S., 2004. The flux of iron from continental shelf sediments: A missing source for global budgets. Geophys. Res. Lett., 31, L12307, doi:10.1029/2004GL020216.

518

Fan, S.-M., Moxim, W. J., Levy II, H., 2006. Aeolian input of bioavailable iron to the

Ocean. Geophys. Res. Lett., 33, L07602, doi:10.1029/2005GL024852.

521

Fukamachi, Y., Mizuta, G., Ohshima, K. I., Talley, L. D., Riser, S. C., Wakatsuchi, M., 2004. Transport and modification processes of dense shelf water revealed by longterm moorings off Sakhalin in the Sea of Okhotsk. J. Geophys. Res., 109, C09S10, doi:10.1029/2003JC001906.

526

527

Galbraith, E. D., Gnanadesikan, A., Dunne, J. P., Hiscock, M. R., 2010: Regional 528 impacts of iron-light colimitation in a global biogeochemical model. Biogeosciences, 7, 1043-1064.

530

531 Garcia, H. E., Locarnini, R. A., Boyer, T. P., Antonov, J. I., Zweng, M. M., Baranova, O.

532 K., Johnson, D. R., 2010. World Ocean Atlas 2009, Volume 4: Nutrients (phosphate, 
Gent, P. R., Willebrand, J., McDougall, T. J., McWilliams, J. C., 1995. Parameterizing 474.

539

Hasumi, H. 2006. CCSR ocean component model (COCO) version 4.0. CCSR Report 25, $103 \mathrm{pp}$.

542

Homoky, W. B., John, S. G., Conway, T. M., Mills, R. A., 2013. Distinct iron isotopic signatures and supply from marine sediment dissolution. Nature Communications, 4, doi:10.1038/ncomms3143.

546

Honeyman, B., Balistrieri, L., Murray J., 1988. Oceanic trace metal scavenging and the importance of particle concentration. Deep Sea Res., Part I, 35, 227-246.

549

Hunke, E. C. Dukowicz, J. K., 1997. An elastic - viscous - plastic model for sea ice dynamics. J. Phys. Oceanogr., 27, 1849-1867.

552 ice and their impact on the nutritional status of surface waters in the southern Okhotsk Sea. Progress in Oceanography, this issue. 
Kitani, K., 1973. An oceanographic study of the Okhotsk Sea: particularly in regard to cold waters. Bulletin of Far Seas Fisheries Research Laboratory, 9, 45-77.

559

560

Mahowald, N., Baker, A., Bergametti, G., Brooks, N., Duce, R., Jickells, T., Kubilay, N., 561 Prospero, J., Tegen, I., 2005. Atmospheric global dust cycle and iron inputs to the ocean. Global Biogeochem. Cycles, 19(4), GB4025, 10.1029/2004GB002402.

563

Marchetti, A., Maldonado, M. T., Lane, E. S., Harrison, P. J., 2006. Iron requirements of 565 the pennate diatom Pseudo-nitzschia: Comparison of oceanic (high-nitrate, low-chlorophyll waters) and coastal species. Limnol. Oceanogr., 51(5), 2092-2101.

567

Martin, J., Knauer, G., Karl, D., Broenkow, W., 1987. VERTEX: Carbon cycling in the northeast Pacific. Deep Sea Res., 34, 267-285.

570

Misumi, K., Tsumune, D., Yoshida, Y., Uchimoto, K., Nakamura, T., Nishioka, J.,

Mitsudera, H., Bryan, F. O., Lindsay, K., Moore, J. K., Doney, S. C., 2011. Mechanisms controlling dissolved iron distribution in the North Pacific: A model study. J. Geophys. Res., 116, G03005, doi:10.1029/2010JG001541.

575

Moore, J. K., Braucher, O., 2008. Sedimentary and mineral dust sources of dissolved 577 iron to the world ocean. Biogeosciences, 5, 631-656.

578

579

Nakamura, T., Awaji, T., 2004. Tidally induced diapycnal mixing in the Kuril Straits 580 and its role in water transformation and transport: A three-dimensional nonhydrostatic 
model experiment. J. Geophys. Res., 109, C09S07, doi:10.1029/2003JC001850.

582

Nakamura T., Toyoda, T., Ishikawa, Y., Awaji, T., 2006. Enhanced ventilation in the

Okhotsk Sea through tidal mixing at the Kuril Straits. Deep Sea Res. Part I, 53, $425-448$.

586

Nakatsuka, T., Yoshikawa, C., Toda, M., Kawamura, K., Wakatsuchi, M., 2002. An extremely turbid intermediate water in the Sea of Okhotsk: Implication for the transport of particulate organic matter in a seasonally ice-bound sea. Geophys. Res. Lett., 29(16), doi:10.1029/2001GL014029.

591

592

Nakatsuka, T., Fujimune, T., Yoshikawa, C., Noriki, S., Kawamura, K., Fukamachi, Y., 593 Mizuta, G., Wakatsuchi, M., 2004. Biogenic and lithogenic particle fluxes in the western region of the Sea of Okhotsk: Implications for lateral material transport and biological productivity. J. Geophys. Res., 109, C09S13, doi:10.1029/2003JC001908.

596

Nihashi, S., Ohshima, K. I., Nakasato, H., 2011. Sea-ice retreat in the Sea of Okhotsk and the ice-ocean albedo feedback effect on it. J. Oceanogr., 67, 551-562, doi:10.1007/s10872-011-0056-x.

600

601 Nishioka, J., Ono, T., Saito, H., Nakatsuka, T., Takeda, S., Yoshimura, T., Suzuki, K.,

602 Kuma, K., Nakabayashi, S., Tsumune, D., Mitsudera, H., Johnson, W. K., Tsuda, A., 603 2007. Iron supply to the western subarctic Pacific: Importance of iron export from the 604 Sea of Okhotsk. J. Geophys. Res., 112, C10012, doi:10.1029/2006JC004055. 
605

606 Nishioka, J., Nakatsuka, T., Watanabe, Y. W., Yasuda, I., Kuma, K., Ogawa, H., Ebuchi, 607 N., Scherbinin, A., Volkov, Y. N., Shiraiwa, T., Wakatsuchi, M., 2013. Intensive mixing 608 along an island chain controls oceanic biogeochemical cycles. Global Biogeochem. Cycles, 609 27, doi:10.1002/gbc.20088.

610

611 Nishioka, J., Nakatsuka, T., Ono, K., Volkov, Y. N., Scherbinin, A., Shiraiwa, T., 2014.

612 Quantitative evaluation of iron transport processes in the Sea of Okhotsk. Progress in 613 Oceanography, this issue.

614

615 Noiri, Y., Kudo, I., Kiyosawa, H., Nishioka, J., Tsuda, A., 2005. Influence of iron and 616 temperature on growth, nutrient utilization ratios and phytoplankton species 617 composition in the western subarctic Pacific Ocean during the SEEDS experiment. 618 Progress in Oceanogr., 64, 149-166, doi:10.1016/j.pocean.2005.02.006.

619

620 Ohshima, K. I., Simizu, D., Itoh, M., Mizuta, G., Fukamachi, Y., Riser, S. C., Wakatsuchi, 621 M., 2004. Sverdrup balance and the cyclonic gyre in the Sea of Okhotsk. J. Phys. 622 Oceanogr., 34, 513-525.

623

624 Ooki, A., Nishioka, J., Ono, T., Noriki, S., 2009. Size dependence of iron solubility of 625 Asian mineral dust particles. J. Geophys. Res., 114, D03202, 626 doi:10.1029/2008JD010804.

627

628 Parekh, P., Follows, M. J., Boyle, E. A., 2005. Decoupling of iron and phosphate in the 
630

631 Parekh, P., Joos, F., Müller, A., 2008. A modeling assessment of the interplay between 632 aeolian iron fluxes and iron-binding ligands in controlling carbon dioxide fluctuations 633 during Antarctic warm events. Paleoceanography, 23, PA4202, 634 doi:10.1029/2007PA001531.

635

636 Perovich, D. K., 1998. The optical properties of sea ice. Physics of ice-covered seas, vol. 1 637 (ed. M. Leppäranta), 195-230.

638

Röske, F., 2001. An atlas of surface fluxes based on the ECMWF re-analysis-A

640 climatological dataset to force global ocean general circulation models. Max-Planck-Institut für Meteorologie Rep. 323, 31 pp.

642

643 Semtner, A. J., Jr., 1976. A model for the thermodynamic growth of sea ice in numerical 644 investigations of climate, J. Phys. Oceanogr., 6, 379-389.

645

646 Shcherbina, A. Y., Talley, L. D., Rudnick, D. L., 2003. Direct observations of North

647 Pacific ventilation: Brine rejection in the Okhotsk Sea, Science, 302, 1952-1955, 648 doi:10.1126/science.1088692.

649

650 Shigemitsu, M., Nishioka, J., Watanabe, Y. W., Yamanaka, Y., Nakatsuka, T., Volkov, Y. 651 N., 2013. Fe/Al ratios of suspended particulate matter from intermediate water in the 
652

653

654

655

656

657

658

659

660

661

662

663

664

665

666

667

668

669

670

671

672

673

674

675

Okhotsk Sea: Implications for long-distance lateral transport of particulate Fe. Mar.

Chem., 157, 41-48.

Takata, H., Kuma, K., Iwade, S., Isoda, Y., Kuroda, H., Senjyu, T., 2005. Comparative vertical distributions of iron in the Japan Sea, the Bering Sea, and the western North Pacific Ocean. J. Geophys. Res., 110, C07004, doi:10.1029/2004JC002783.

Takata, H., Kuma, K., Isoda, Y., Otosaka, S., Senjyu, T., Minagawa, M., 2008. Iron in the Japan Sea and its implications for the physical processes in deep water. Geophysical Research Letters, 35(2), L02606, doi:10.1029/2007GL031794.

Tsuda, A., Takeda, S., Saito, H., Nishioka, J., Nojiri, Y., Kudo, I., Kiyosawa, H., Shiomoto, A., Imai, K., Ono, T., Shimamoto, A., Tsumune, D., Yoshimura, T., Aono, T., Hinuma, A., Kinugasa, M., Suzuki, K., Sohrin, Y., Noiri, Y., Tani, H., Deguchi, Y., Tsurushima, N., Ogawa, H., Fukami, K., Kuma, K., Saino, T., 2003. A mesoscale iron enrichment in the western subarctic Pacific induces large centric diatom bloom. Science, 300(5621), 958-961.

Tsuda, A., Takeda, S., Saito, H., Nishioka, J., Kudo, I., Nojiri, Y., Suzuki, K., Uematsu, M., Wells, M. L., Tsumune, D., Yoshimura, T., Aono, T., Aramaki, T., Cochlan, W. P., Hayakawa, M., Imai, K., Isada, T., Iwamoto, Y., Johnson, W. K., Kameyama, S., Kato, S., Kiyosawa, H., Kondo, Y., Levasseur, M., Machida, R. J., Nagao, I., Nakagawa, F., Nakanishi, T., Nakatsuka, S., Narita, A., Noiri, Y., Obata, H., Ogawa, H., Oguma, K., Ono, T., Sakuragi, T., Sasakawa, M., Sato, M., Shimamoto, A., Takata, H., Trick, C. G., 
676 Watanabe, Y. W., Wong, C. S., Yoshie, N., 2007. Evidence for the grazing hypothesis:

677 grazing reduces phytoplankton responses of the HNLC ecosystem to iron enrichment in

678 the Western Subarctic Pacific (SEEDS II). J. Oceanogr., 63, 983-994.

679

680 Uchimoto, K., Nakamura, T., Mitsudera, H., 2011a. Tracing dense shelf water in the Sea 681 of Okhotsk with an ocean circulation model. Hydro. Res. Lett., 5, 1-5, 682 doi:10.3178/hrl.5.1.

683

684 Uchimoto, K., Nakamura, T., Nishioka, J., Mitsudera, H., Yamamoto-Kawai, M., 685 Misumi, K., Tsumune, D., 2011b. Simulations of chlorofluorocarbons in and around the 686 Sea of Okhotsk: Effects of tidal mixing and brine rejection on the ventilation. J. Geophys. 687 Res., 116, C02034, doi:10.1029/2010JC006487.

688

689 Ye, Y., Wagener, T., Völker, C., Guieu, C., Wolf-Gladrow, D., 2011. Dust deposition: iron 690 source or sink? A case study. Biogeosciences, 8, 2107-2124. 
691

692

693

694

695

696

697

698

699

700

701

702

703

704

705

706

707

708

709

710

711

712

713

714

Figure captions

Figure 1. Model domain with geographical names.

Figure 2. Schematic representation of the phosphorus cycle in the model.

Figure 3. Dust deposition distribution (g/m²/y) from Mahowald et al. (2005).

Figure 4. The boundary conditions for iron within the Sea of Japan (red) and the southern boundary in the Pacific (black), which is also the initial condition.

Figure 5. The boundary condition for iron along the eastern boundary.

Figure 6. The iron concentration (nM) at the sea surface in July. The solubility of dust iron is (a) 0 , (b) 1 , (c) 5, (d) $10 \%$.

Figure 7. The iron concentration (nM) on the $26.8 \sigma_{\theta}$ surface in July. The solubility of dust iron is (a) 0, (b) 1 , (c) 5 , (d) $10 \%$.

Figure 8. The surface phosphate concentration ( $\mu \mathrm{M})$ of WOA09 in (a) January, (b) April, (c) July, and (d) October.

Figure 9. The phosphate concentration $(\mu \mathrm{M})$ at the sea surface in July in experiments with the dust iron solubility of (a) $0 \%$, (b) $1 \%$, (c) $5 \%$, and (d) $10 \%$.

Figure 10. The phosphate concentration at the sea surface in July. $\mathrm{K}_{\mathrm{Fe}}=0.5$. (a) $\mathrm{a}=0.5$, (b) $\alpha=0.75,(c) \alpha=1.0$.

Figure 11. The iron concentration $(\mathrm{nM})$ on the $26.8 \sigma_{\theta}$ surface and on the vertical section along the DSW line (see Fig. 12a) in the standard case in (a)(e) January, (b) (f) April, (c) (g) July, and (d)(h) October, respectively. Numbers on top of Figs. 11e-h correspond to those in Fig. 12a.

Figure 12. The iron concentration (nM) on the $26.8 \sigma_{\theta}$ surface and on the vertical section along the DSW line in July in the experiment without sedimentary iron source. Red line in (a) shows the DSW line. 
Figure 13. Comparison of modeled (red) and observed (black) iron profile. Observed

716 data were along $52.25^{\circ} \mathrm{N}$ from $143.5^{\circ} \mathrm{E}$ to $146^{\circ} \mathrm{E}$ in August 2006 by Nishioka et al.

717 (2014), and modeled data are along $52.0^{\circ} \mathrm{N}$ and $52.5^{\circ} \mathrm{N}$ from $144.5^{\circ} \mathrm{E}$ to $145.5^{\circ} \mathrm{E}$ in

718 August and September.

719 Figure 14. The $\mathrm{PO}_{4}$ distribution ( $\mu \mathrm{M}$ ) from (a) January to (l) December.

720 Figure 15. The $\mathrm{PO}_{4}$ distribution in the standard case along the DSW line in (a) January,

721 (b) April, (c) July, and (d) October.

722 Figure 16. The $\mathrm{PO}_{4}$ distribution in WOA09 along the DSW line in (a) January, (b) April,

(c) July, and (d) October.

Figure 17. The DOP distribution in the standard case along the DSW line in (a) January, (b) April, (c) July, and (d) October.

Figure 18. The continental shelf in the Sea of Okhotsk which was divided into four parts; NW (red), NC (green), NE (blue), and OT (yellow).

Figure 19. The difference of the iron concentration (nM) on $26.8 \sigma_{\theta}$ surface in July between each experiment and NoSed case. (a) NW1, (b) NC1, (c) NE1, (d) OT1.

Figure 20. The iron concentration in DSW vs. the iron flux in each of the four parts. The cross is no iron source experiment. w: NW, c: NC, e: NE, o:OT

Figure 21. The differences of the iron concentration (nM) in July between (a) NW2 and NW1, (b) NW3 and NW2, (c) NW4 and NW3, and (d) NW5 and NW4.

Figure 22. The differences of the iron concentration in July between (a) NW2O1 and ALL1, and (b) ALL1 and NW0O1.

Figure 23. The iron concentration (nM) on the vertical section along the DSW line in

738 Figure 24. The iron concentration (nM) on the vertical section along the DSW line in 
739 July in the experiment with $\mathrm{W}_{\text {sink }}$ (a) 1450, and (b) $5800 \mathrm{~m} / \mathrm{y}$.

740

741

742 Table captions

743 Table 1. Parameters of the biogeochemical model in the standard case that are different

744 from values used in Parekh et al. (2005).

745 Table 2. Experimental cases. All the experiments are conducted without the dust iron

746 source, and only sedimentary iron flux is used as an iron source within the Sea of

747 Okhotsk. 


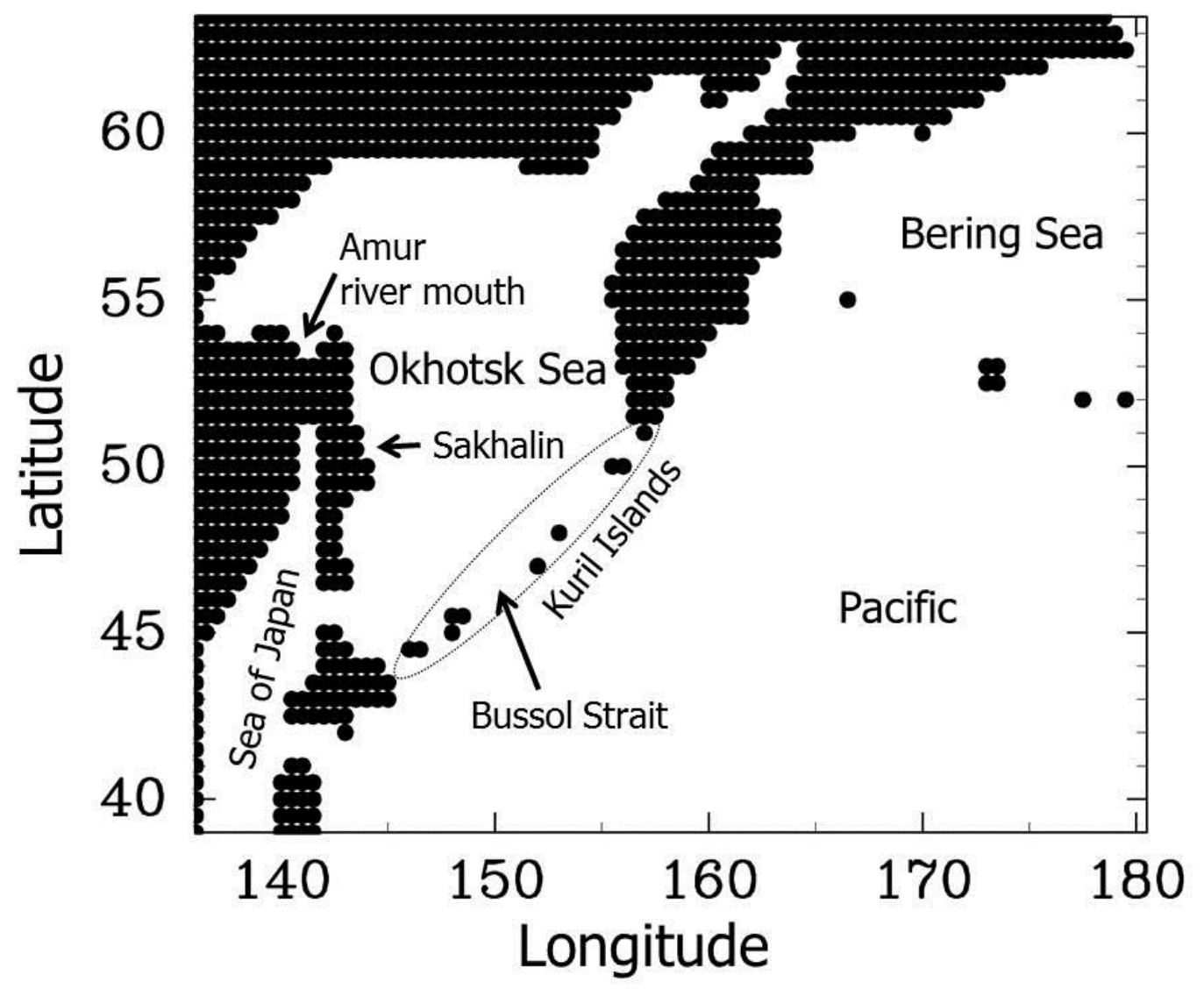

Figure 1. Model domain with geographical name. 


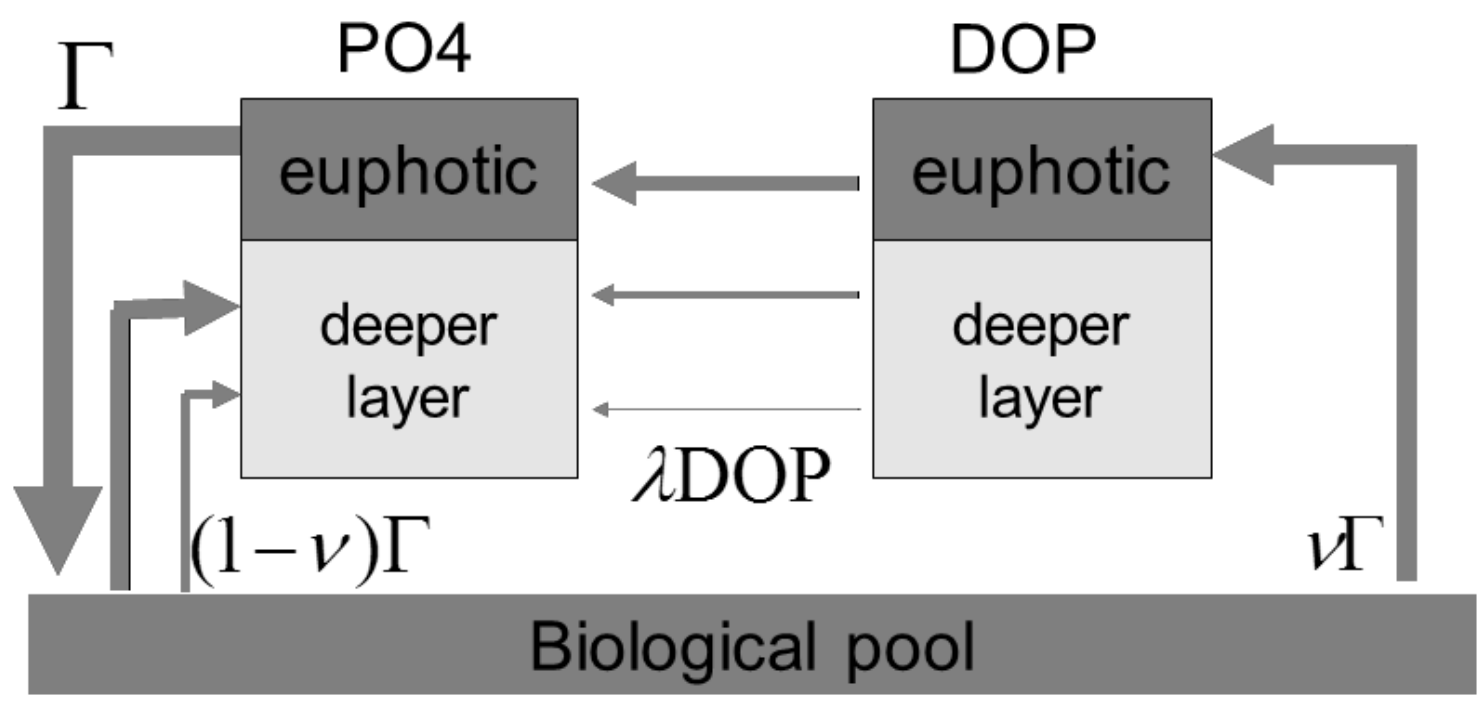

Figure 2. Schematic representation of the phosphorus cycle in the model. 

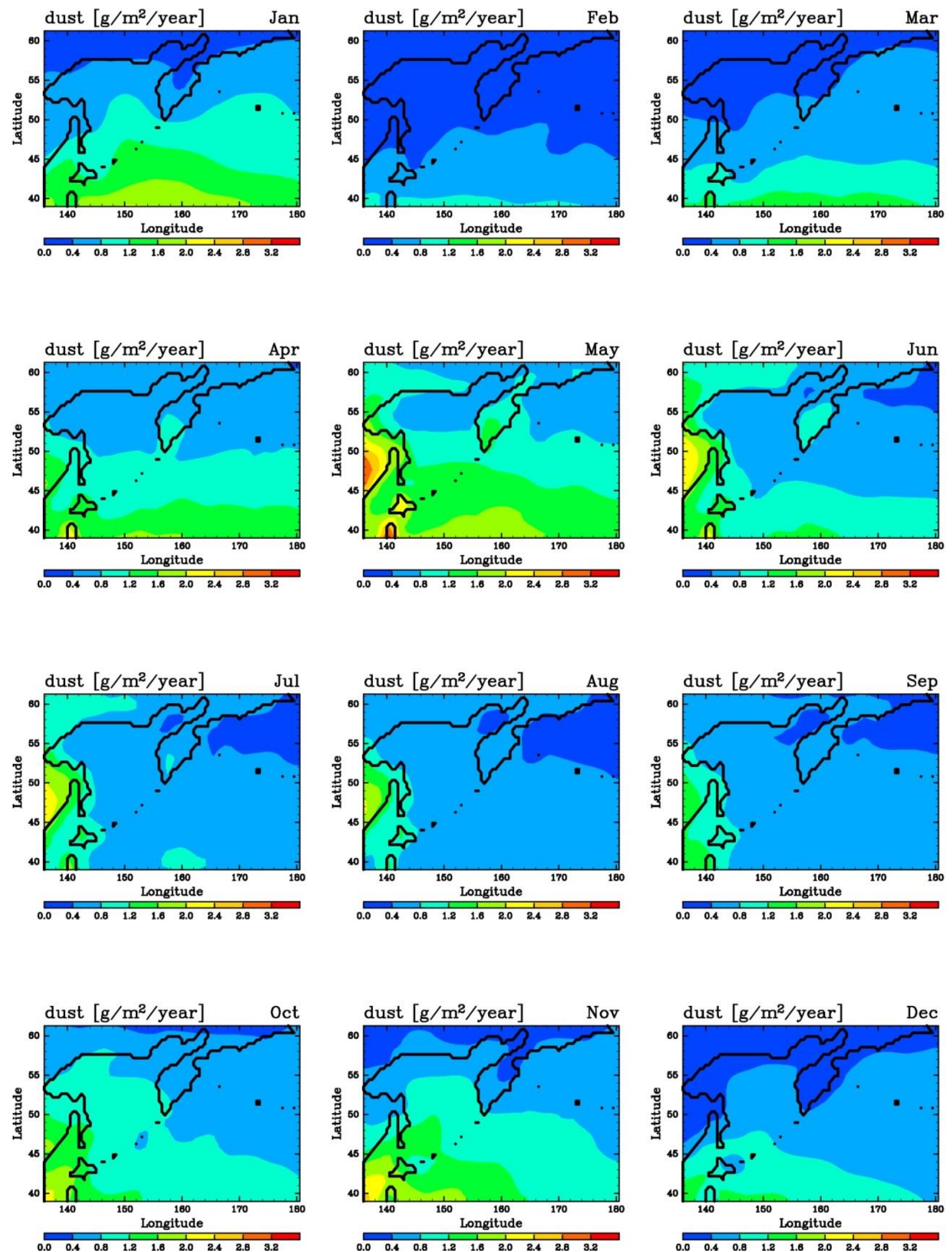

Figure 3. Dust deposition distribution (g/m²/y) from Mahowald et al. (2005). 


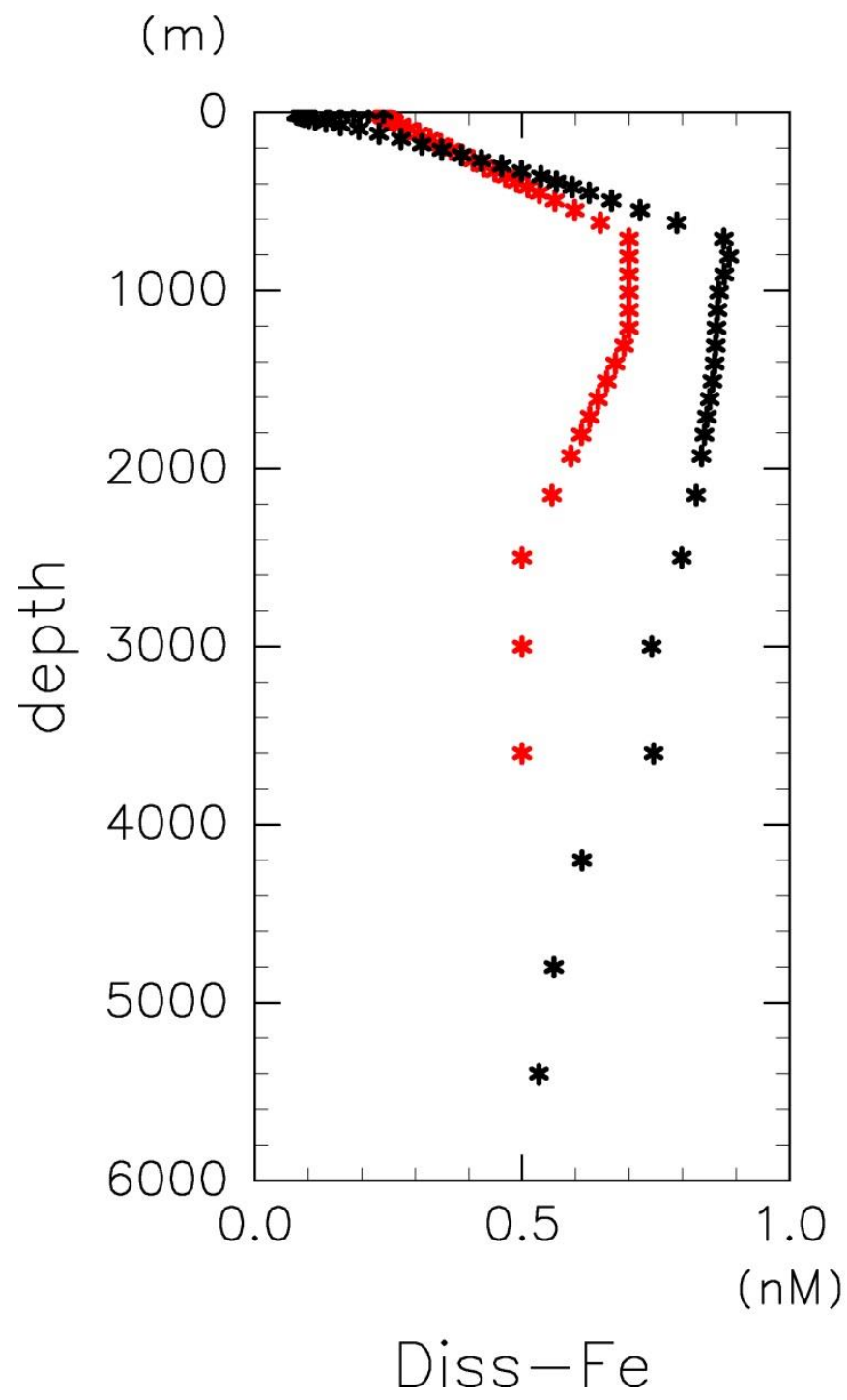

Figure 4. The boundary conditions for iron within the Sea of Japan (red) and the southern boundary in the Pacific (black), which is also the initial condition. 


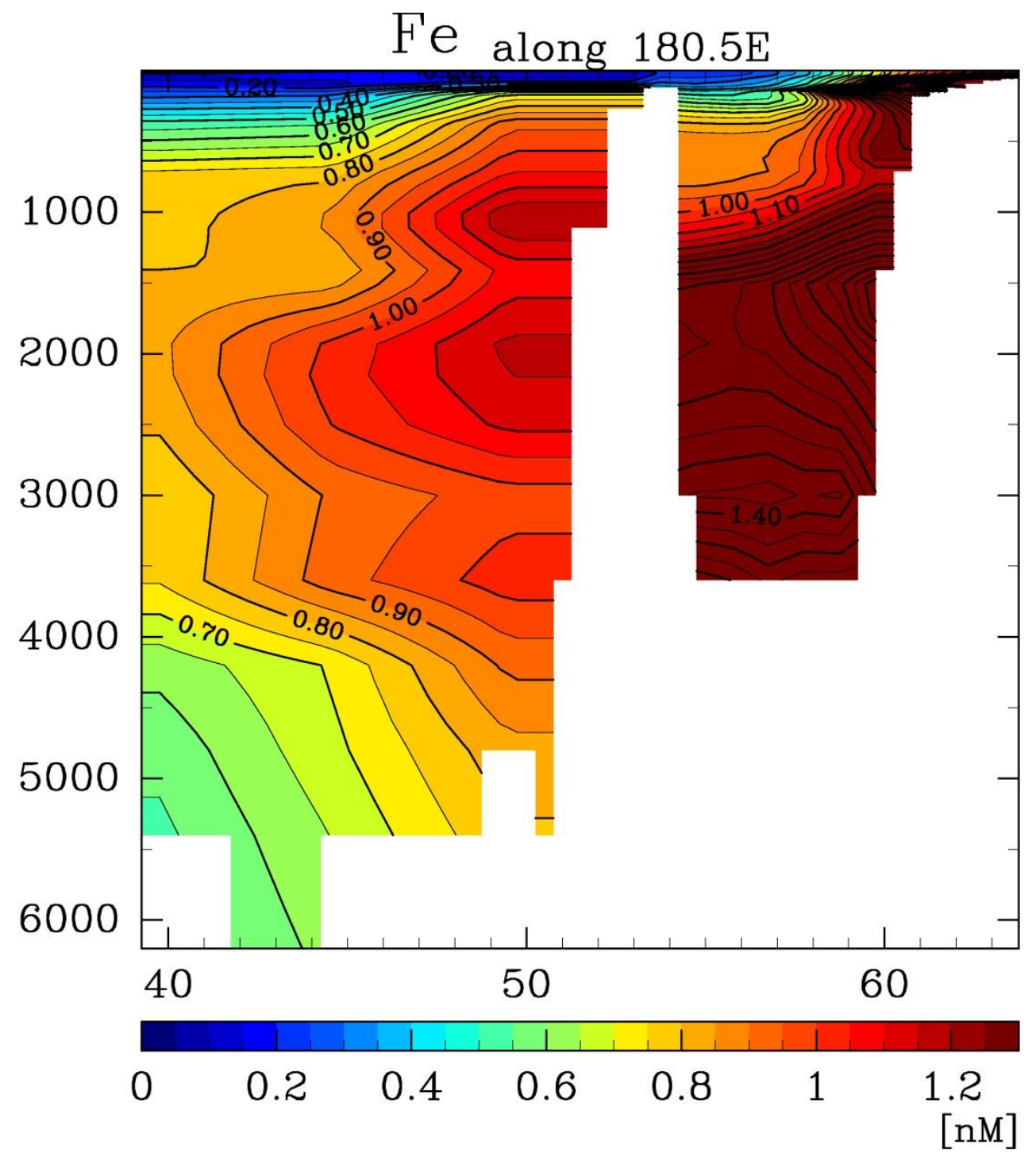

Figure 5. The boundary condition for iron along the eastern boundary. 

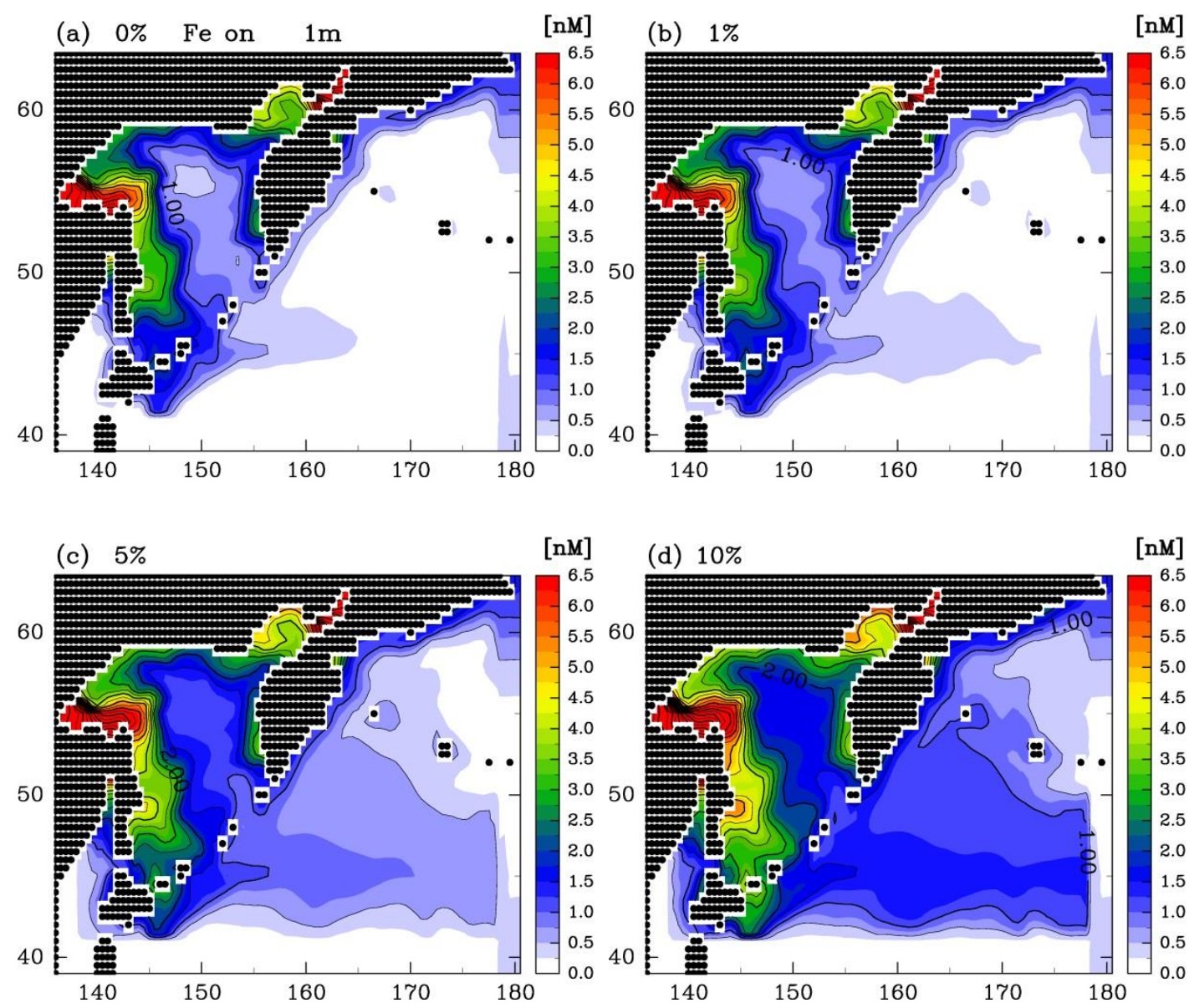

Figure 6. The iron concentration $(\mathrm{nM})$ at the sea surface in July. The solubility of dust iron is (a) 0 , (b) 1 , (c) 5 , (d) $10 \%$. 

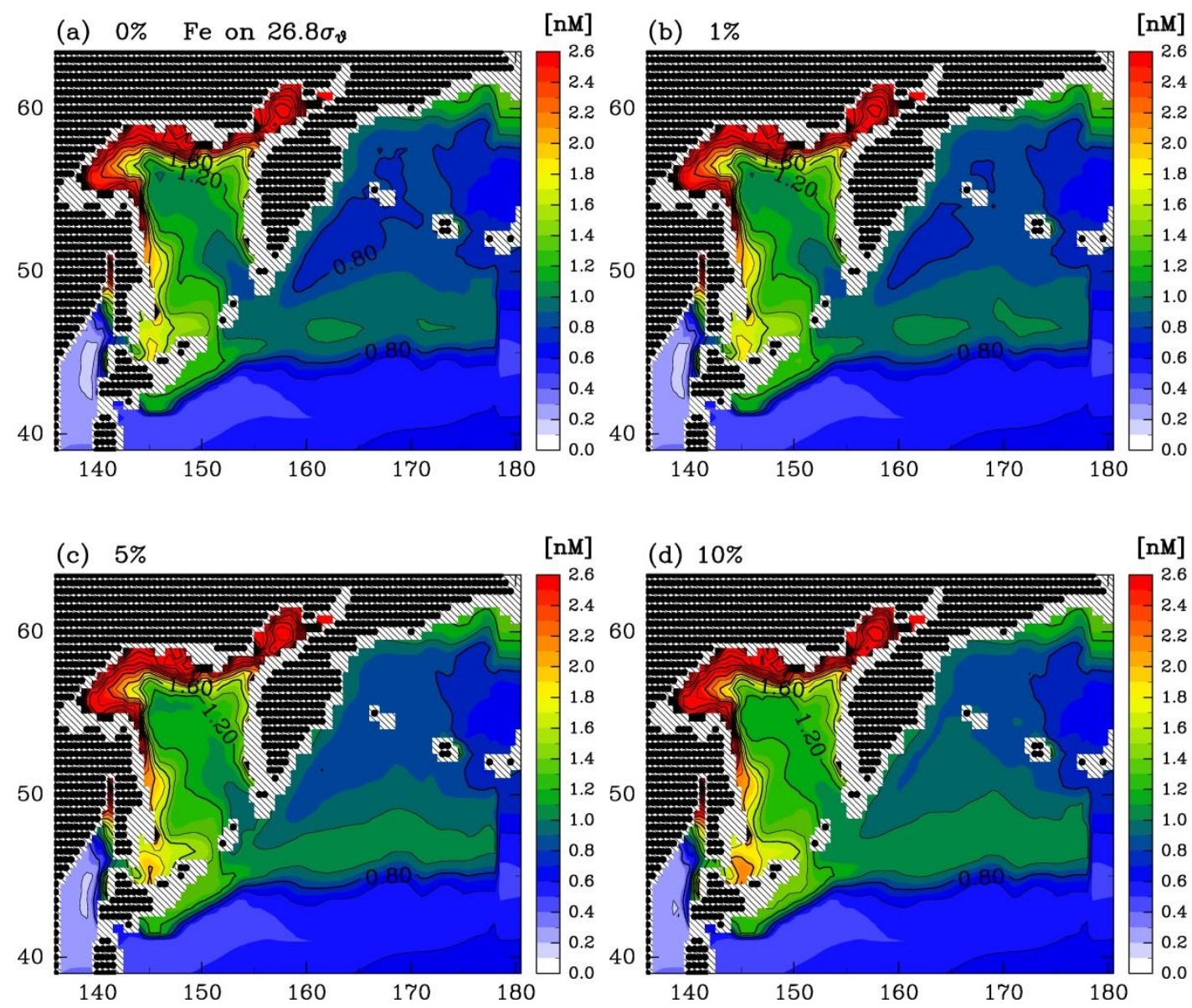

Figure 7. The iron concentration (nM) on the $26.8 \sigma_{\theta}$ surface in July. The solubility of dust iron is (a) 0 , (b) 1 , (c) 5 , (d) $10 \%$. 

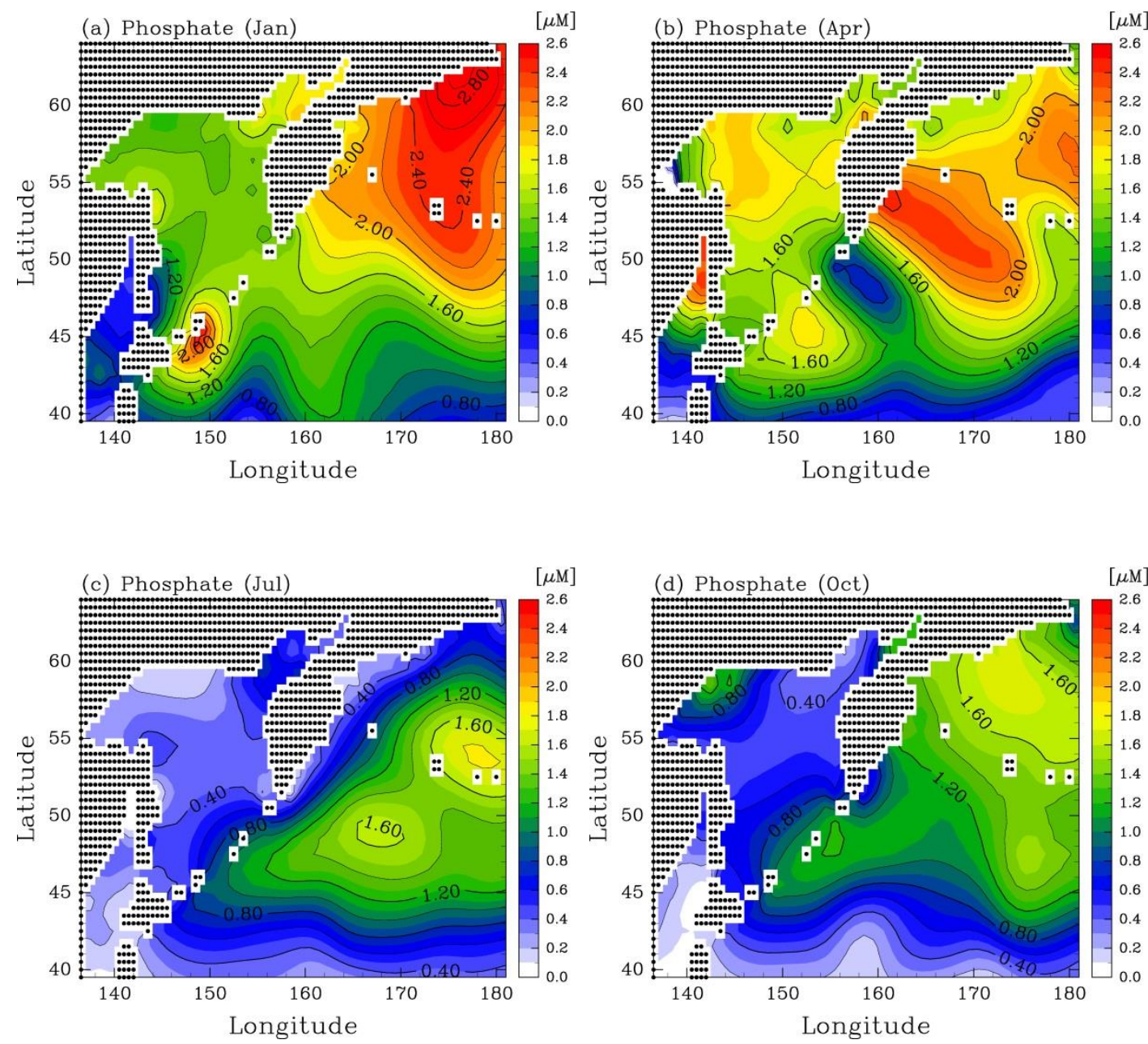

Figure 8. The surface phosphate concentration ( $\mu \mathrm{M}$ ) of WOA09 in (a) January, (b) April, (c) July, and (d) October. 



Figure 9. The phosphate concentration $(\mu \mathrm{M})$ at the sea surface in July in experiments with the dust iron solubility of (a) $0 \%$, (b) $1 \%$, (c) $5 \%$, and (d) $10 \%$. 

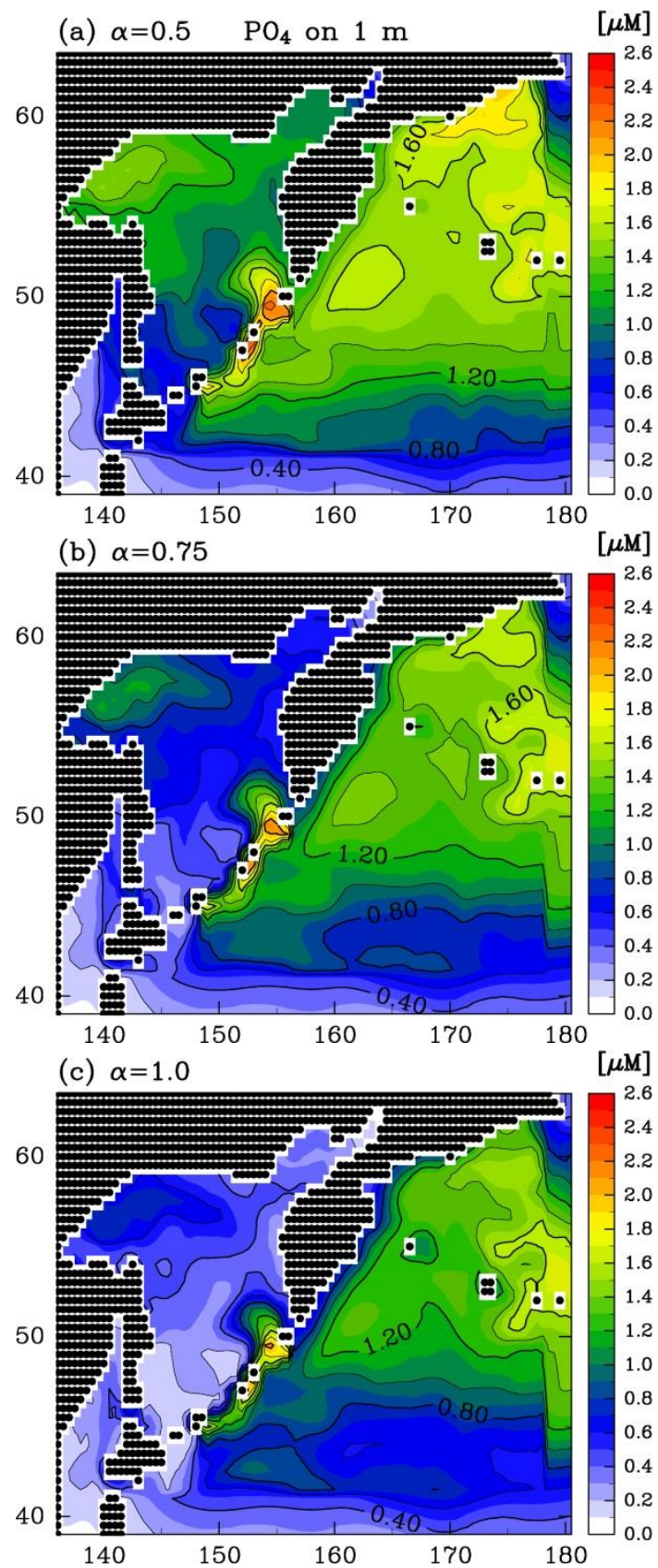

Figure 10. The phosphate concentration at the sea surface in July. $\mathrm{K}_{\mathrm{Fe}}=0.5$. (a) $\mathrm{a}=0.5$, (b) $\alpha=0.75,(c) \alpha=1.0$. 

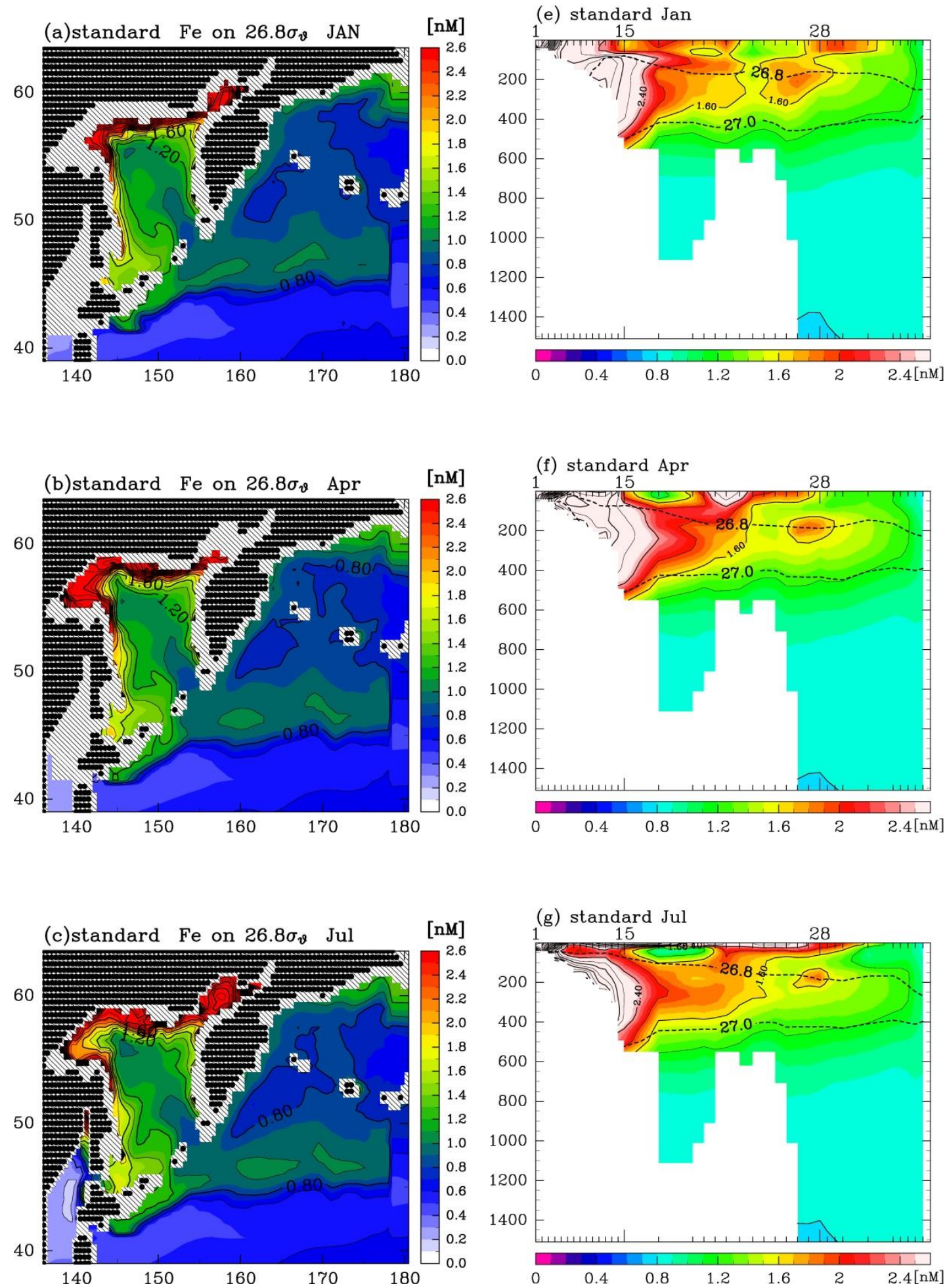

Figure 11 (continued) 


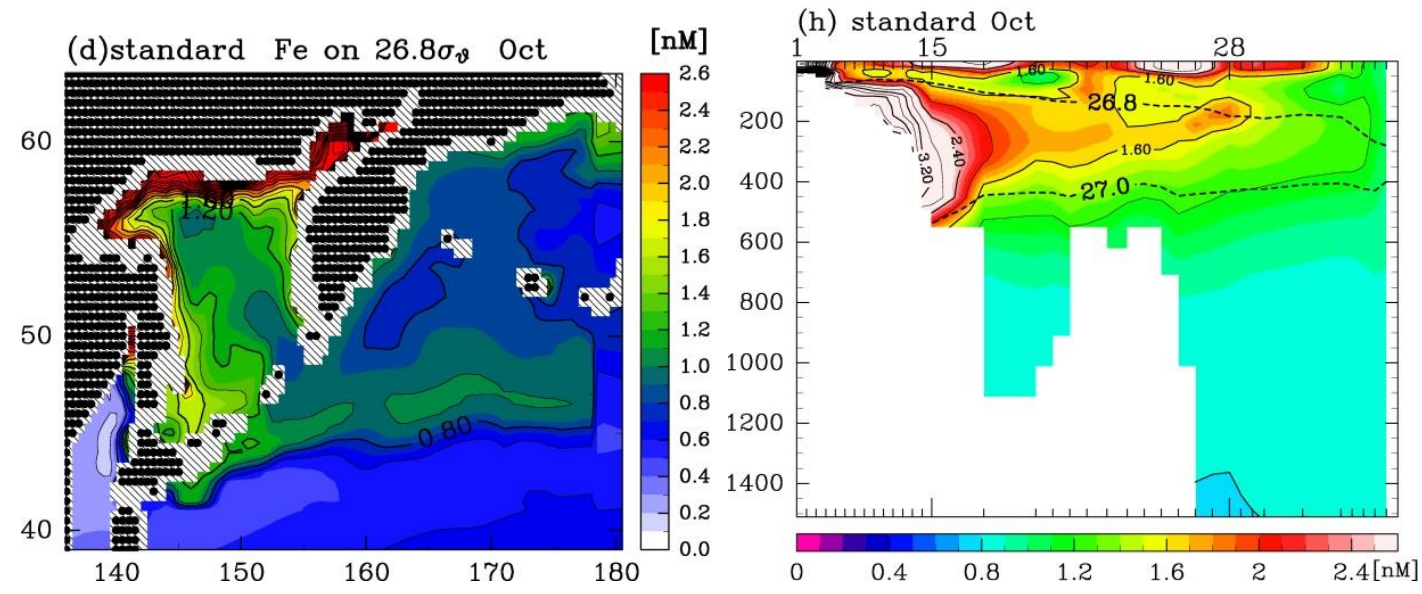

Figure 11. The iron concentration (nM) on the $26.8 \sigma_{\theta}$ surface and on the vertical section along the DSW line (see Fig. 12a) in the standard case in (a)(e) January, (b) (f) April, (c) (g) July, and (d)(h) October, respectively. Numbers on top of Figs. 7e-h correspond to those in Fig. 12a. 




Figure 12. The iron concentration (nM) on the $26.8 \sigma_{\theta}$ surface and on the vertical section along the DSW line in July in the experiment without sedimentary iron source. Red line in (a) shows the DSW line. 


\section{$\left(\mathrm{kg} / \mathrm{m}^{3}\right)$}

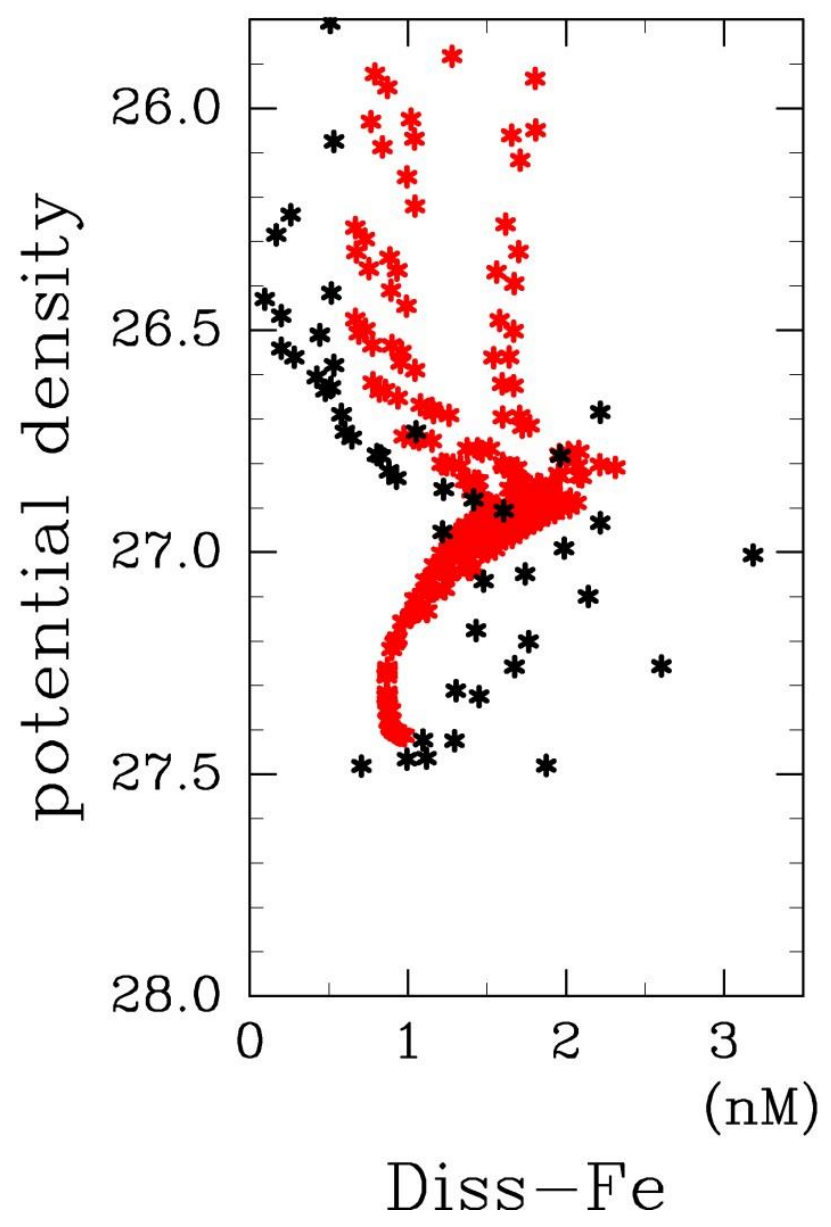

Figure 13. Comparison of modeled (red) and observed (black) iron profile. Observed data were along $52.25^{\circ} \mathrm{N}$ from $143.5^{\circ} \mathrm{E}$ to $146^{\circ} \mathrm{E}$ in August 2006 by Nishioka et al. (2014), and modeled data are along $52.0^{\circ} \mathrm{N}$ and $52.5^{\circ} \mathrm{N}$ from $144.5^{\circ} \mathrm{E}$ to $145.5^{\circ} \mathrm{E}$ in August and September. 
(a) $\mathrm{PO}_{4}$ on $1 \mathrm{~m} \quad 18 / 01[\mu \mathrm{M}]$

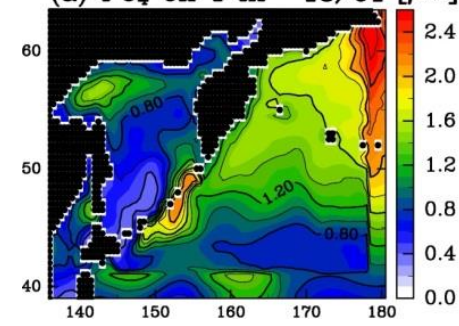

(d) $\mathrm{PO}_{4}$ on $1 \mathrm{~m} \quad 18 / 04[\mu \mathrm{M}]$

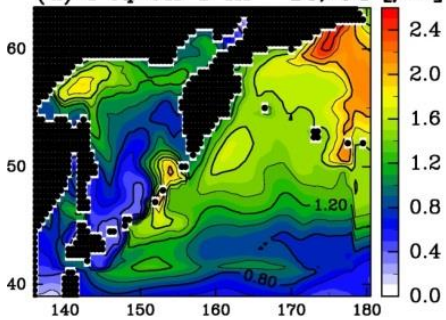

(g) $\mathrm{PO}_{4}$ on $1 \mathrm{~m} \quad 17 / 07[\mu \mathrm{M}]$

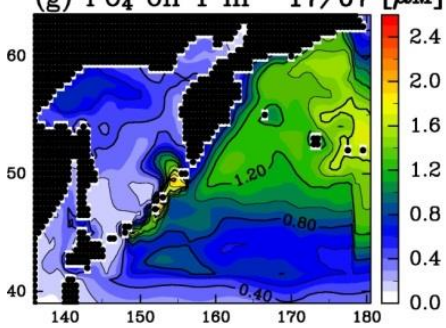

(j) $\mathrm{PO}_{4}$ on $1 \mathrm{~m} \quad 17 / 10[\mu \mathrm{M}]$

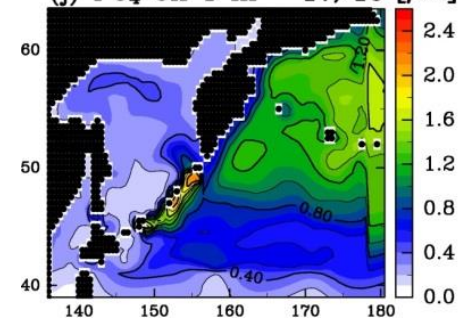

(b) $\mathrm{PO}_{4}$ on $1 \mathrm{~m} \quad 18 / 02[\mu \mathrm{M}]$

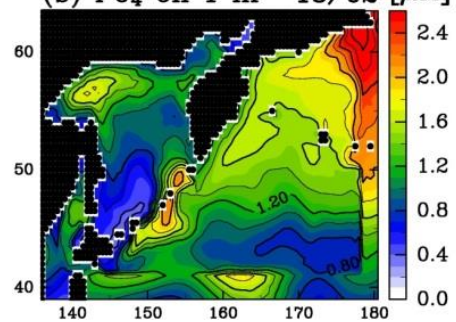

(e) $\mathrm{PO}_{4}$ on $1 \mathrm{~m} \quad 18 / 05[\mu \mathrm{M}]$

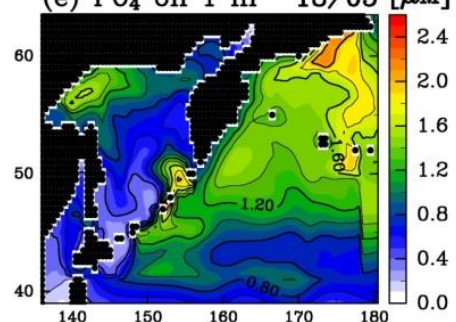

(h) $\mathrm{PO}_{4}$ on $1 \mathrm{~m} \quad 17 / 08[\mu \mathrm{M}]$



(k) $\mathrm{PO}_{4}$ on $1 \mathrm{~m} \quad 17 / 11[\mu \mathrm{M}]$

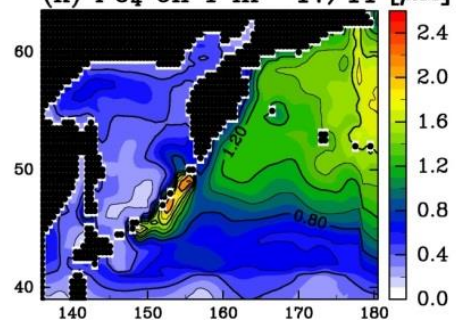

(c) $\mathrm{PO}_{4}$ on $1 \mathrm{~m} \quad 18 / 03[\mu \mathrm{M}]$

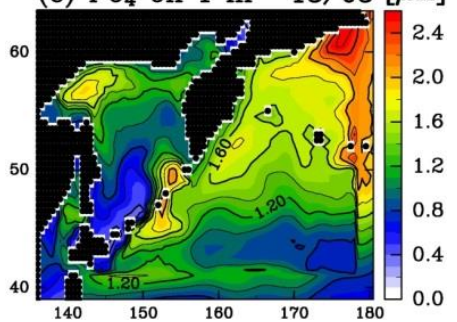

(f) $\mathrm{PO}_{4}$ on $1 \mathrm{~m} \quad 18 / 06[\mu \mathrm{M}]$

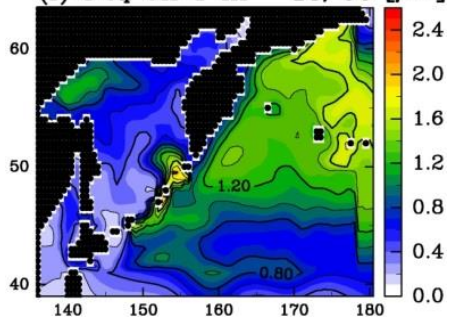

(i) $\mathrm{PO}_{4}$ on $1 \mathrm{~m} \quad 17 / 09[\mu \mathrm{M}]$

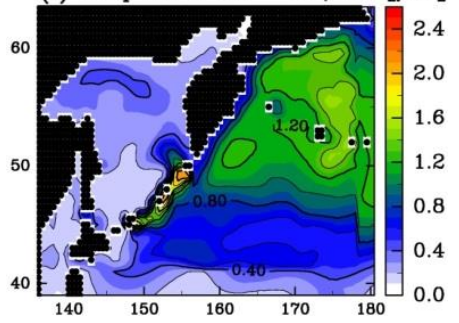

(l) $\mathrm{PO}_{4}$ on $1 \mathrm{~m} \quad 17 / 12[\mu \mathrm{M}]$

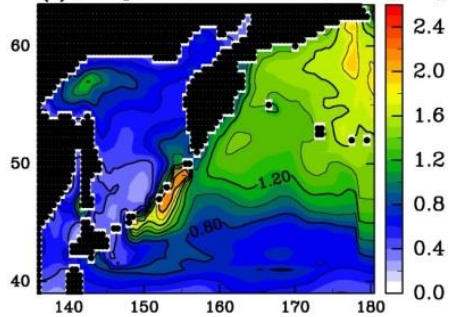

Figure 14. The PO4 distribution ( $\mu$ M) from (a) January to (l) December. 

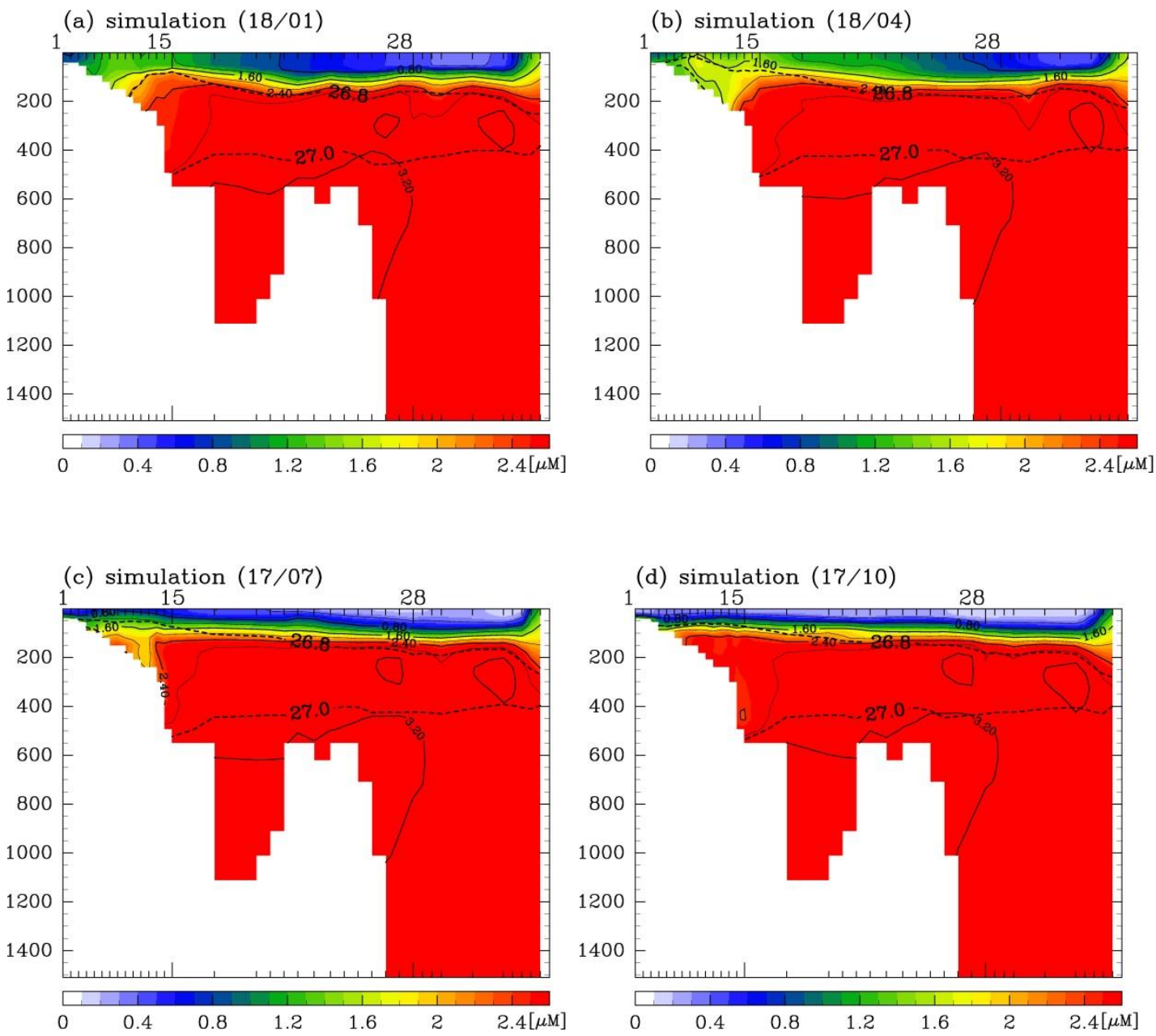

Figure 15. The PO4 distribution in the standard case along the DSW line in (a) January, (b) April, (c) July, and (d) October. 

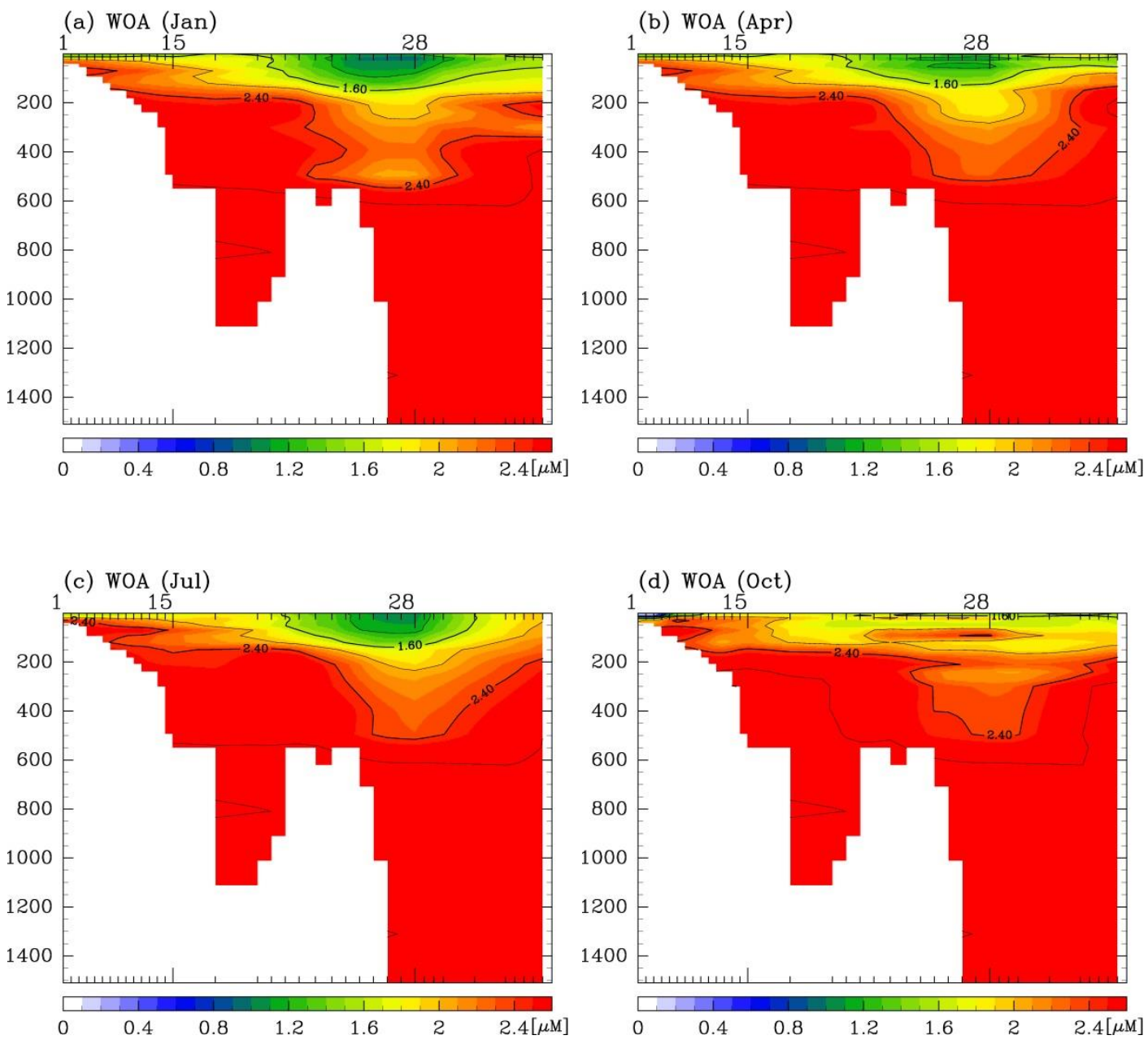

Figure 16. The PO4 distribution in WOA along the DSW line in (a) January, (b) April, (c) July, and (d) October. 
(a) simulation (18/01)

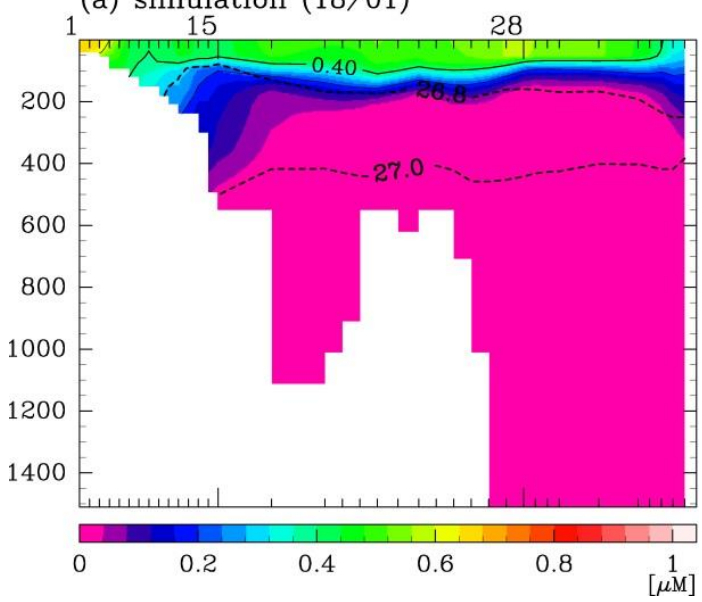

(c) simulation (17/07)

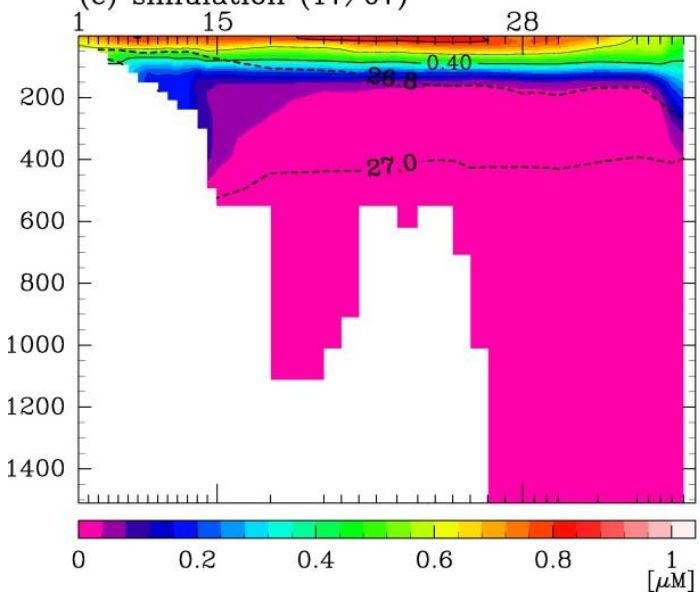

(b) simulation (18/04)



(d) simulation $(17 / 10)$



Figure 17. The DOP distribution in the standard case along the DSW line in (a) January, (b) April, (c) July, and (d) October. 


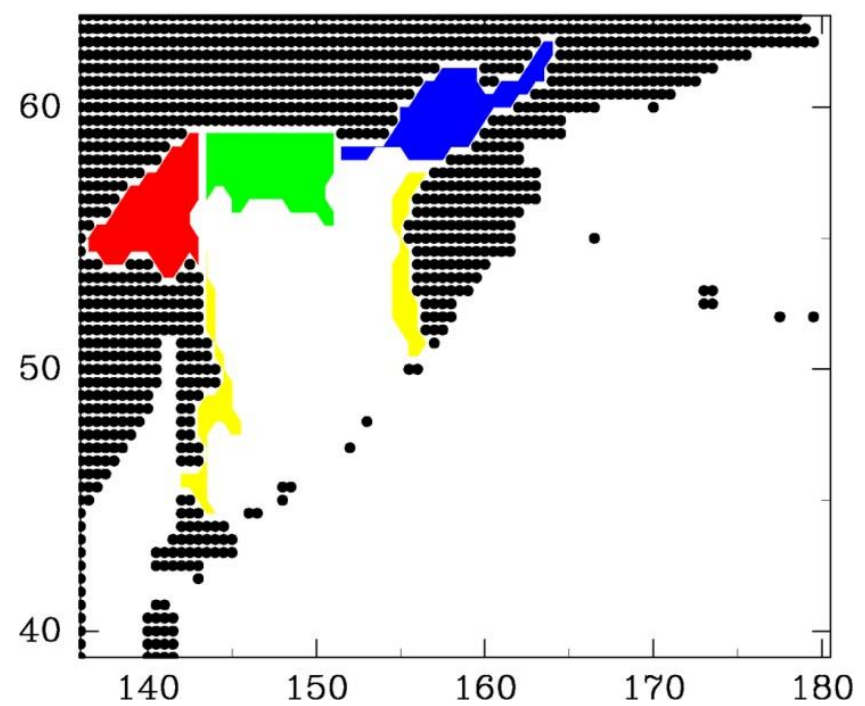

Figure 18. The continental shelves in the Sea of Okhotsk divided into four parts; NW (red), NC (green), NE (blue), and OT (yellow). 

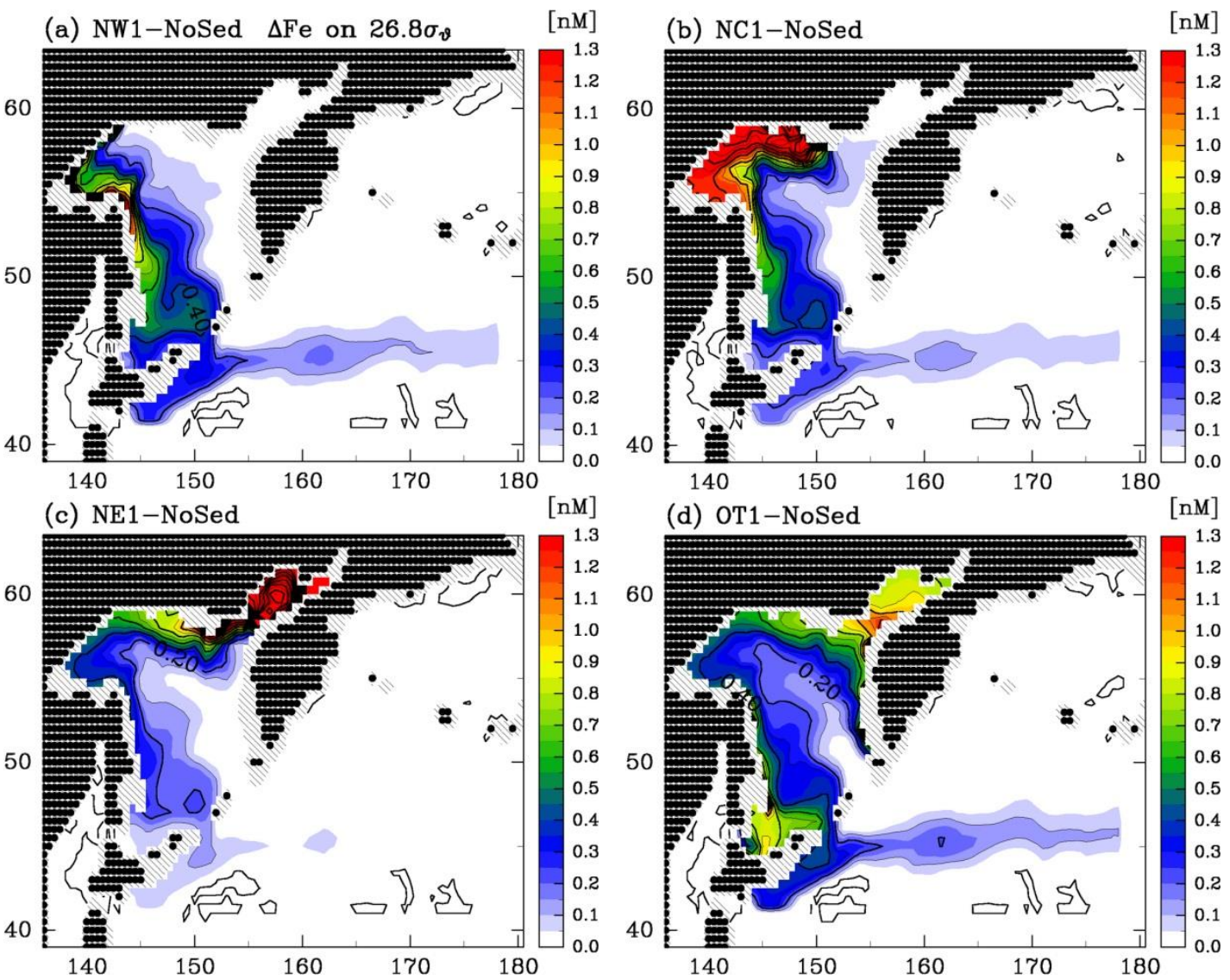

Figure 19. The difference of the iron concentration (nM) on $26.8 \sigma_{\theta}$ surface in July between each experiment and NoSed case. (a) NW1, (b) NC1, (c) NE1, (d) OT1. 




Figure 20. The iron concentration in DSW vs. the iron flux in each part. The cross is no iron source experiment. w: NW, c: NC, e: NE, o:OT 

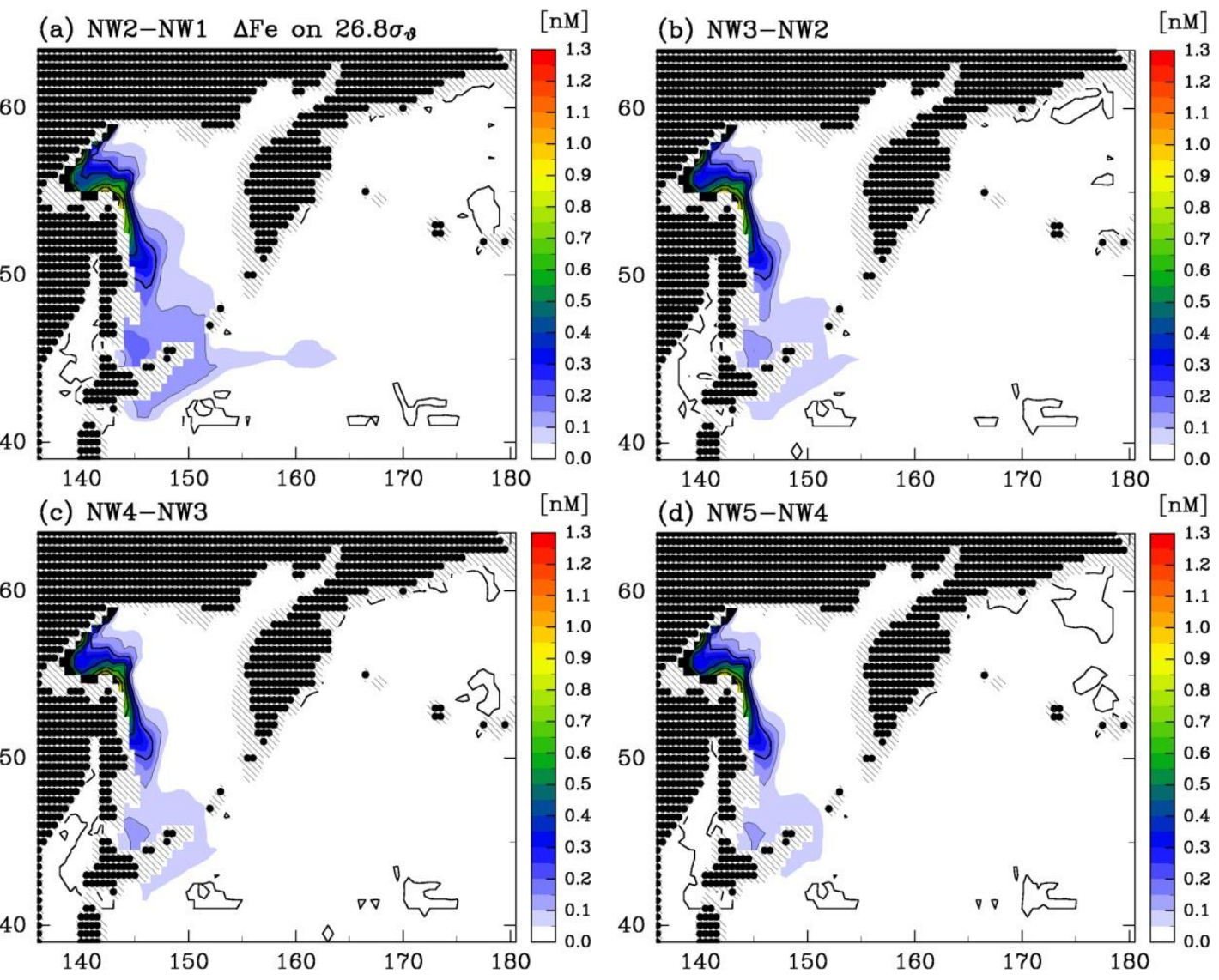

Figure 21. The differences of the iron concentration (nM) in July between (a) NW2 and NW1, (b) NW3 and NW2, (c) NW4 and NW3, and (d) NW5 and NW4. 

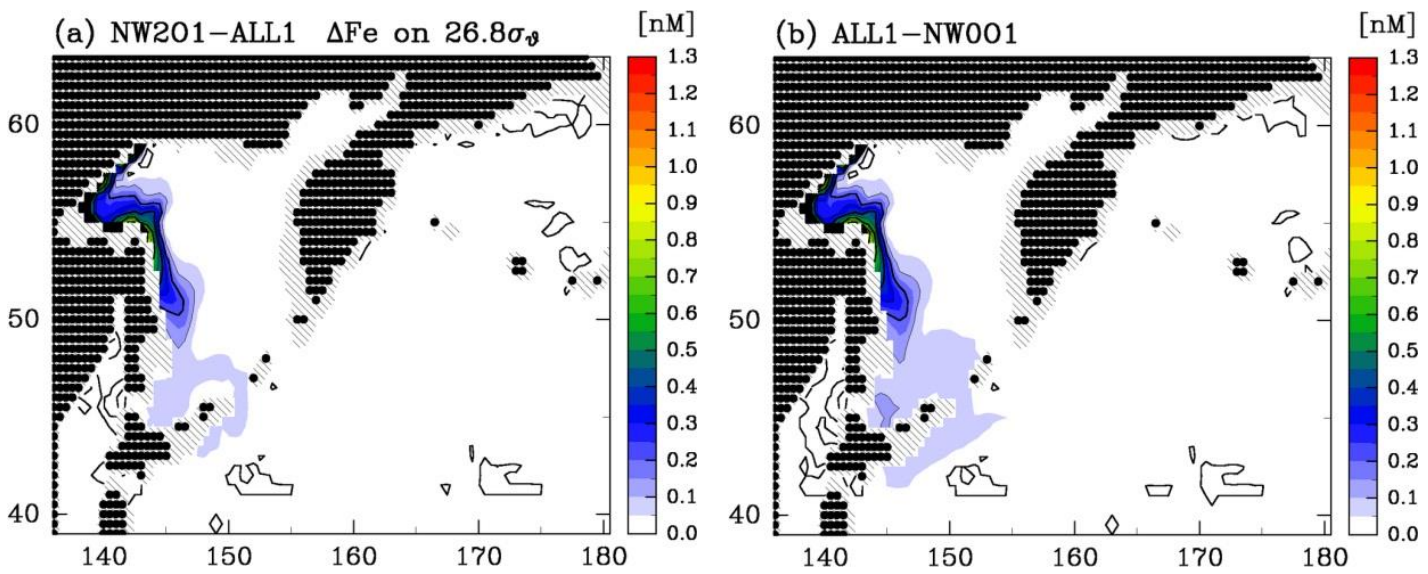

Figure 22. The differences of the iron concentration in July between (a) NW2O1 and ALL1, and (b) ALL1 and NW0O1. 
(a) $\tau=0.1$

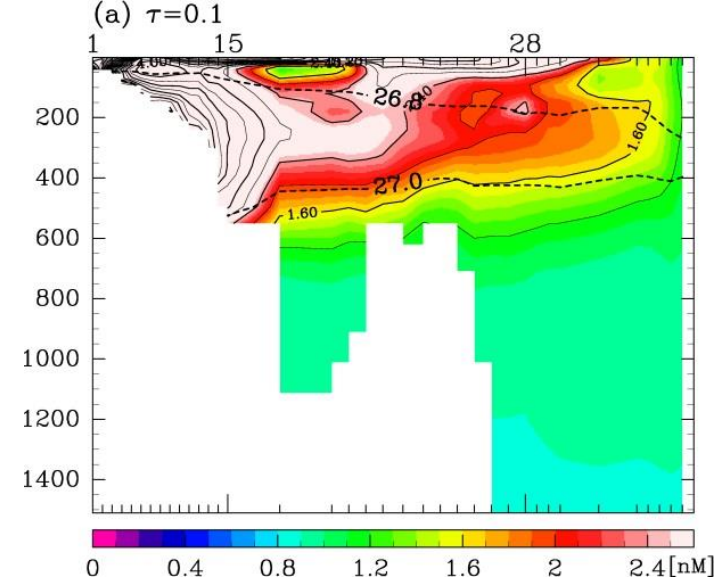

(b) $\tau=0.4$



Figure 23. The iron concentration (nM) on the vertical section along the DSW line in July in the experiment with $\tau$ (a) 0.1, and (b) 0.4. 

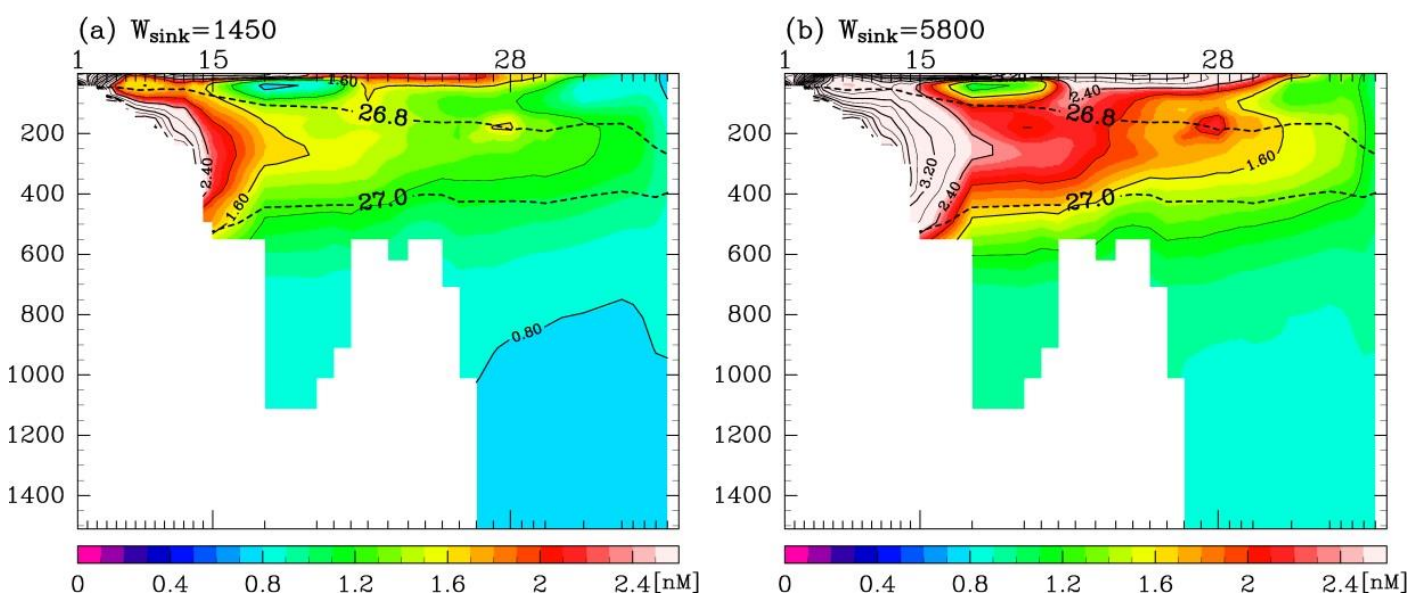

Figure 24. The iron concentration (nM) on the vertical section along the DSW line in July in the experiment with $\mathrm{W}_{\text {sink }}$ (a) 1450 , and (b) $5800 \mathrm{~m} / \mathrm{y}$. 
Table 1. Parameters of the biogeochemical model in the standard case that are different from values used in Parekh et al. (2005).

\begin{tabular}{lcl}
\hline Definition & Symbol & Value \\
\hline euphotic zone & & $135 \mathrm{~m}$ \\
irradiation decay scale (sea) & & $30 \mathrm{~m}$ \\
irradiation decay scale (ice) & $\kappa^{-1}$ & $1.5 \mathrm{~cm}$ \\
albedo of sea ice (young ice) & $\gamma_{I}$ & 0.36 \\
albedo of sea ice (others) & $\gamma_{I}$ & 0.7 \\
sedimentary iron flux & & $1 \mathrm{\mu mol} \mathrm{Fe} \mathrm{m}^{-2} \mathrm{~d}^{-1}$ \\
maximum export rate & $\alpha$ & 1.0 \\
iron half saturation constant & $\mathrm{K}_{\mathrm{Fe}}$ & $0.5 \mathrm{nM}$ \\
total ligand & & $1.2 \mathrm{nM}$ \\
\hline
\end{tabular}


Table 2. Experimental cases. All the experiments are conducted without the dust iron source, and only sedimentary iron flux is used as an iron source within the Sea of Okhotsk.

\begin{tabular}{|c|c|}
\hline Case name & Sedimentary iron flux \\
\hline NoSed & No sedimentary iron flux \\
\hline NWx, NCx, NEx, OTx & 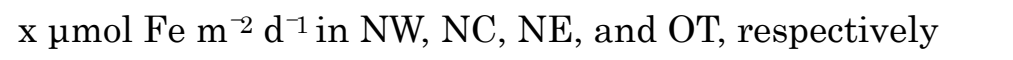 \\
\hline NW2O1 & $2 \mu \mathrm{mol} \mathrm{Fe} \mathrm{m}{ }^{-2} \mathrm{~d}^{1}$ in NW and $1 \mu \mathrm{mol} \mathrm{Fe} \mathrm{m} \mathrm{m}^{-2} \mathrm{~d}^{1}$ in the others \\
\hline NW0O1 & No flux in NW and $1 \mu \mathrm{mol} \mathrm{Fe} \mathrm{m}{ }^{-2} \mathrm{~d}^{-1}$ in the others \\
\hline ALL1 & $1 \mu \mathrm{mol} \mathrm{Fe} \mathrm{m}^{-2} \mathrm{~d}^{11}$ in $\mathrm{NW}, \mathrm{NC}, \mathrm{NE}$, and OT. \\
\hline
\end{tabular}


